\title{
Article \\ Blood Lead Level and Renal Impairment among Adults: A Meta-Analysis
}

\author{
Saruda Kuraeiad (D) and Manas Kotepui *
}

Citation: Kuraeiad, S.; Kotepui, M Blood Lead Level and Renal Impairment among Adults: A Meta-Analysis. Int. J. Environ. Res. Public Health 2021, 18, 4174. https:// doi.org/10.3390/ijerph18084174

Academic Editor: Paul B. Tchounwou

Received: 8 March 2021

Accepted: 14 April 2021

Published: 15 April 2021

Publisher's Note: MDPI stays neutral with regard to jurisdictional claims in published maps and institutional affiliations.

Copyright: (c) 2021 by the authors. Licensee MDPI, Basel, Switzerland. This article is an open access article distributed under the terms and conditions of the Creative Commons Attribution (CC BY) license (https:// creativecommons.org/licenses/by/ $4.0 /)$.
Medical Technology, School of Allied Health Sciences, Walailak University, Tha Sala, Nakhon Si Thammarat 80160, Thailand; saruda.ku@wu.ac.th

* Correspondence: manas.ko@wu.ac.th

\begin{abstract}
Background: The adult population in lead-related occupations or environmentally exposed to lead may be at risk for renal impairment and lead nephropathy. This meta-analysis aims to determine the impact of blood lead level (BLL) on renal function among middle-aged participants. Methods: Cross-sectional, longitudinal, or cohort studies that reported BLL and renal function tests among adult participants were retrieved from PubMed, Scopus, and ISI Web of Science. Relevant studies were included and assessed for quality using the Newcastle-Ottawa Scale (NOS). The pooled mean BLL of participants with a high BLL $(\geq 30 \mu \mathrm{g} / \mathrm{dL})$, moderate BLL $(20-30 \mu \mathrm{g} / \mathrm{dL})$, and low BLL $(<20 \mu \mathrm{g} / \mathrm{dL})$ was estimated using the random effects model. The pooled mean differences in BLL, blood urea nitrogen (BUN), creatinine, uric acid, and creatinine clearance between the exposed and non-exposed participants were estimated using the random effects model. Meta-regression was performed to demonstrate the association between the effect size (ES) of the pooled mean BLL and renal function. Heterogeneity among the included studies was assessed using the Cochrane $\mathrm{Q}$ and $\mathrm{I}^{2}$ statistics. Cochrane $\mathrm{Q}$ with a $p$ value less than 0.05 and $\mathrm{I}^{2}$ more than $50 \%$ demonstrated substantial heterogeneity among the studies included. Publication bias was assessed using the funnel plot between the effect size and standard error of the effect size. Results: Out of 1657 articles, 43 were included in the meta-analysis. The meta-analysis demonstrated that the pooled mean BLL in the participants with a high BLL, moderate BLL, and low BLL was $42.41 \mu \mathrm{g} / \mathrm{dL}$ (95\% confidence interval (CI): 42.14-42.67, $\mathrm{I}^{2}: 99.1 \%$ ), $22.18 \mu \mathrm{g} / \mathrm{dL}$ (95\% CI: 21.68-22.68, $\mathrm{I}^{2}: 60.4 \%$ ), and $2.9 \mu \mathrm{g} / \mathrm{dL}$ (95\% CI: 2.9-2.9, $\mathrm{I}^{2}: 100 \%$ ), respectively. The mean BLL of the exposed participants was higher than that of the non-exposed participants (weighted mean difference (WMD): 25.5, $p<0.0001,95 \% \mathrm{CI}$ : 18.59-32.45, $\mathrm{I}^{2}$ : 99.8\%, 17 studies). The mean BUN (WMD: 1.66, $p<0.0001,95 \%$ CI: 0.76-2.55, $\mathrm{I}^{2}: 76 \%, 10$ studies) and mean creatinine (WMD: 0.05, $p=0.007,95 \% \mathrm{CI}: 0.01-0.08, \mathrm{I}^{2}:$ : 76.8\%, 15 studies) in the exposed participants were higher than those in the non-exposed participants. The mean creatinine clearance in the exposed participants was lower than that in the non-exposed participants (standard mean difference (SMD): $\left.-0.544, p=0.03,95 \% \mathrm{CI}:-1.035-(-0.054), \mathrm{I}^{2}: 96.2 \%\right)$. The meta-regression demonstrated a significant positive effect of BLL on BUN $(p=0.022$, coefficient: 0.75 , constant: $-3.7,10$ studies). Conclusions: BLL was observed to be associated with abnormal renal function test parameters, including high BUN, high creatinine, and low creatinine clearance. Moreover, BUN seemed to be the most valuable prognostic marker for lead-induced renal impairment. Therefore, regular checks for renal function among lead-exposed workers should be a priority and publicly promoted.
\end{abstract}

Keywords: blood lead level; renal insufficiency; renal impairment; BUN; creatinine

\section{Background}

Lead is a heavy metal and toxicant to the human body [1]. The most common sources of lead in lead-related occupations come from batteries, radiator manufacturing, lead refineries, paints, and ceramics [2]. In addition, lead is distributed in the environment as contaminated dust, in drinking water, and in soil where humans can be exposed through 
inhalation and ingestion [3]. When lead is absorbed into the blood, over $95 \%$ of it is bound to erythrocytes and distributed through the body [4].

Blood lead level (BLL) is widely used as a biomarker for lead exposure because it reflects the current exposure to lead [2]. Although the lead level in the environment has decreased for many years, diseases induced by lead have still been reported [3]. The benchmark based on the US National Health and Nutrition Examination Survey, which enrolled both children and adults, found a decrease in the mean BLL from $1.65 \mu \mathrm{g} / \mathrm{dL}$ in 1999-2000 to $0.84 \mu \mathrm{g} / \mathrm{dL}$ in 2013-2014 [5]. The US Department of Health and Human Services suggested that the BLL in adults should be below $10 \mu \mathrm{g} / \mathrm{dL}$ [4]. However, there is no defined safe value for lead, and a reference value for BLL has not been reported. In children, BLL at less than $10 \mu \mathrm{g} / \mathrm{dL}$ can cause intelligence deficits, anemia, and growth retardation [6,7]. In adults, lead can cause osteoporosis, hypertension, cardiovascular diseases, anemia, memory loss, and liver and renal impairment [8].

Evidence from epidemiological studies has demonstrated an association between BLL and lead nephropathy, where even BLL below $10 \mu \mathrm{g} / \mathrm{dL}$ can cause harmful effects on renal function $[9,10]$. A previous study demonstrated that BLL over $7.5 \mu \mathrm{g} / \mathrm{dL}$ presented a higher risk for renal impairment (odds ratio $(\mathrm{OR})=1.92,95 \%$ confidence interval $(\mathrm{CI})$ : 1.18-3.10) and hyperuricemia [11]. Furthermore, investigators have shown that high BLL $(>40 \mu \mathrm{g} / \mathrm{dL})$ was associated with renal impairment among occupational workers [12-15]. Moreover, mortality from chronic kidney disease has increased among American lead workers [16]. Lead-induced lead nephropathy interferes with renal function in glomeruli and renal tubules, where the proximal tubule is reported to be highly sensitive to lead in short durations of high exposure, while chronic lead exposure induces glomerular sclerosis, and interstitial fibrosis induces irreversible renal injury [17]. A previous study suggested that frequent exposure to lead could induce the formation of lead-protein complexes deposited on the glomerulus and proximal tubules, which in turn reduces the glomerular filtration of urea and creatinine, leading to their retention in the plasma [17]. Studies have demonstrated that occupational lead workers, such as workers in battery plants, spray painters, and smelt lead workers, had significantly higher BLL than nonoccupational lead workers $[7,13,17]$. Therefore, lead-exposed workers have a higher risk for renal impairment [4]. Renal impairment can be assessed using renal function parameters, such as blood urea nitrogen (BUN), serum creatinine, uric acid, and creatinine clearance [18]. Studies by investigators on lead-exposed adult workers in Taiwan, South Korea, and Nigeria have demonstrated a decrease in creatinine clearance and an increase in BUN, serum creatinine, and uric acid among lead-exposed workers $[14,15,19]$. A study among South African battery plant workers showed an increase in serum creatinine and uric acid in leadexposed workers, but they did not find any changes in BUN and creatinine clearance [13]. Nevertheless, some studies have demonstrated that all renal indicators were normal in lead-exposed workers [20].

A previous meta-analysis of BLL in Iranian lead workers demonstrated that the highest mean BLL was $72.58 \mu \mathrm{g} / \mathrm{dL}$ [95\% CI: 26.06-119.10] among lead-zinc mine workers [21]. Moreover, the most recent meta-analysis investigating the association between BLL and cognitive function demonstrated that BLL was significantly higher in exposed than in nonexposed participants. In addition, an increase in BLL translated into a decline in cognitive abilities among exposed participants [8]. Although the meta-analysis of BLL related to works or the meta-analysis of BLL-related cognitive function have been investigated, to our knowledge, there is no meta-analysis investigating the association between BLL and renal function in adults currently. Therefore, the present study aimed to determine the impact of BLL on renal function among the adult population by determining the difference in BLL and the difference in renal function test parameters, including BUN, creatinine, creatinine clearance, and uric acid, among exposed and non-exposed participants. Moreover, metaregression analysis was also performed to determine the association between BLL and renal function test parameters. 


\section{Methods}

\subsection{Protocol and Registration}

The systematic review and meta-analysis followed the Preferred Reporting Items for Systematic Reviews and Meta-Analyses (PRISMA) guidelines [22]. The protocol of this study was registered at the International Prospective Register of Systematic Reviews (PROSPERO) with registration number CRD42021232630 [23].

\subsection{Searches}

The search terms in combination with the Boolean operator ("blood lead" OR "lead exposure" OR "lead toxicity" OR "lead poisoning") AND (renal OR kidney) and (adult OR "middle-aged" OR worker) were used to retrieve potentially relevant studies in three databases: Medline, Scopus, and ISI Web of Science. The keywords "lead", "renal", and "middle-aged" were checked with the Medical Subject Heading (MeSH term) to identify the relevant search terms. The searches were performed on 15 January 2020. The search terms are provided in Table S1.

\subsection{Eligibility Criteria}

The inclusion criteria for this study included any cross-sectional, longitudinal, or cohort studies that reported on BLL and renal function among adult participants. The exclusion criteria excluded any studies with the following characteristics: animal models, case control studies on chronic kidney diseases or end-stage renal disease or patients with diabetes mellitus at enrollment, non-English language studies, studies with a small sample size (fewer than 10 participants) including case reports/case series/comments/errata/correspondences/short reports, in vitro studies, studies where the data on BLL or renal function tests could not be extracted, studies using the same data or participants for a different research question, and studies that measured co-exposure of lead and other metals.

\subsection{Study Selection and Data Extraction}

Any studies that met the eligibility criteria were selected by two independent authors (SK, MK). Any disagreement between the two authors in selecting the studies was resolved by discussion for consensus. Data extraction was also performed by two independent authors (SK, MK). The following data were extracted from the included studies: name of the first author, publication year, study site, year that the study was conducted, and participant data, including mean age, gender, BLL, BUN, creatinine, uric acid, creatinine clearance or estimated glomerular filtration rate (eGFR), and the status of renal impairment (if applicable). The data were extracted into a standardized pilot datasheet for further analysis.

\subsection{Quality of the Included Studies (Risk of Bias)}

The quality of the included studies was assessed using the Newcastle-Ottawa Scale (NOS) to assess the quality of non-randomized studies in meta-analyses [24]. The NOS scale assessing the quality of the included studies used the star system to judge the included studies on three main perspectives: selection of the study groups, comparability of the groups, and ascertainment of outcome of interest. Any studies rated with a score of at least eight indicated a "high quality" study, whereas any studies rated between 5-7 indicated a "moderate quality" study. NOS scores lower than 5 indicated a "low quality" study.

\subsection{Study Outcomes}

The primary outcome of this study was to explore the association between BLL and renal function. The secondary outcome was the pooled mean difference in BLL between the exposed and non-exposed participants. The third outcome was the pooled mean difference in BUN, creatinine, uric acid, and creatinine clearance between the exposed and non-exposed participants. The fourth outcome was the pooled mean BLL among participants with a high BLL $(\geq 30 \mu \mathrm{g} / \mathrm{dL})$, moderate BLL $(20-30 \mu \mathrm{g} / \mathrm{dL})$, and low BLL 
$(<20 \mu \mathrm{g} / \mathrm{dL})$. Cutoff values of $<20 \mu \mathrm{g} / \mathrm{dL}, 20-30 \mu \mathrm{g} / \mathrm{dL}$, and $>30 \mu \mathrm{g} / \mathrm{dL}$ were used to indicate lead exposure among participants, as previously described by Lim et al. [25].

\subsection{Statistical Analysis}

The mean BLL reported in the included studies was used to analyze the pooled mean BLL among the exposed participants. However, as the non-exposed participants were a low-risk group and showed a low BLL, the mean BLL of non-exposed or controls was not estimated in this study. The median with rank or interquartile rank of BLL and renal parameters reported in the included studies was transformed into the mean and standard deviation (SD), as reported elsewhere [26]. The unit of BLL and renal parameters, including $\mathrm{BUN}$, creatinine, and uric acid, used for analyses were $\mu \mathrm{g} / \mathrm{dL}$ and $\mathrm{mg} / \mathrm{dL}$, respectively; hence, any studies that reported a different unit then had data converted to $\mu \mathrm{g} / \mathrm{dL}$ of BLL and $\mathrm{mg} / \mathrm{dL}$ of renal parameters using the calculator available online [27]. The pooled mean BLL and 95\% confidence interval of the included studies were estimated using the random-effects model. The pooled mean differences in BLL, BUN, creatinine, and uric acid between the exposed and non-exposed participants were estimated using the random-effects model and presented as weighted mean differences (WMDs) with 95\% CIs. WMD is the difference in means between the mean value in exposed and non-exposed participants. As the mean creatinine clearance was reported in the included studies in different units, the standard mean difference (SMD) was used to estimate the difference in mean creatinine clearance between exposed and non-exposed participants. Meta-regression was performed to demonstrate the association between the effect size (ES) or WMD of BLL and renal function test parameters, including BUN, creatinine, BUN/creatinine ratio, creatinine clearance, and uric acid. Heterogeneity among the included studies was assessed using the Cochrane $\mathrm{Q}$ and $\mathrm{I}^{2}$ statistics. Cochrane $\mathrm{Q}$ with a $p$ value less than 0.05 and $\mathrm{I}^{2}$ more than $50 \%$ demonstrated substantial heterogeneity among the included studies [28]. Of the heterogeneity that existed, the random-effects model was used for estimating the pooled variables, and if heterogeneity did not exist, the fixed-effects model was used for estimating the pooled variables. Subgroup analysis of BLL was performed to demonstrate any differences among the groups of exposed participants. Publication bias among the included studies was assessed by visualizing the funnel plot asymmetry. If the funnel plot demonstrated an asymmetrical distribution, Egger's test was used to confirm whether the asymmetrical distribution of the funnel plot was caused by the small-study effects. All analyses were performed using Stata Version 14.2 (StataCorp, College Station, TX, USA).

\section{Results}

\subsection{Search Results}

Overall, 1657 articles were retrieved from the searches of three databases. After removing 676 duplicate articles, 981 articles were screened for potentially relevant articles through title and abstract screening. As a result, 754 articles were excluded due to their having no relevance to the present study. The full texts of the 227 articles that remained were examined according to the eligibility criteria, and 184 articles were excluded (Figure 1). Finally, 43 articles $[3,4,7,11,13,15-17,19,20,25,29-60]$ met the study criteria and were included in the study.

\subsection{Characteristics of the Included Studies}

The 43 included studies were published between 1987 and 2020 and were conducted in 18 countries in 4 regions. Most of the studies were conducted in Asia (20/43, 46.5\%), America $(11 / 43,25.6 \%)$, Europe $(8 / 43,18.6 \%)$, and Africa (4/43, 9.3\%). In Asia, the studies were conducted in the Republic of Korea (5/20, 25\%), India (4/20, 20\%), China (4/20, 20\%), and Taiwan $(2 / 20,10 \%)$, and the remaining 5 studies $(25 \%)$ were from Thailand, Turkey, Iran, Japan, and Singapore. In America, the studies were conducted in the United States of America (9/11, 81.8\%), and 2 studies (18.2\%) were conducted in Brazil and Mexico. In Europe, the studies were conducted in Belgium (3/8, 37.5\%) and Sweden (3/8, 37.5\%), 
and 2 studies (25\%) were conducted in the Netherlands and United Kingdom. In Africa, the studies were conducted in Nigeria (3/4, 75\%) and South Africa (1/4, 25\%). Most of the included studies were cross-sectional studies $(32 / 43,74.4 \%)$, and the rest $(11 / 43,25.6 \%)$ were cohort, longitudinal, or retrospective studies. Most of the studies determined BLL in exposed and non-exposed participants $(18 / 43,41.9 \%)$, population-based surveys $(10 / 43$, $23.2 \%)$, and BLL in only in exposed participants $(15 / 43,24.8 \%)$. The characteristics of the included studies are shown in Table 1.

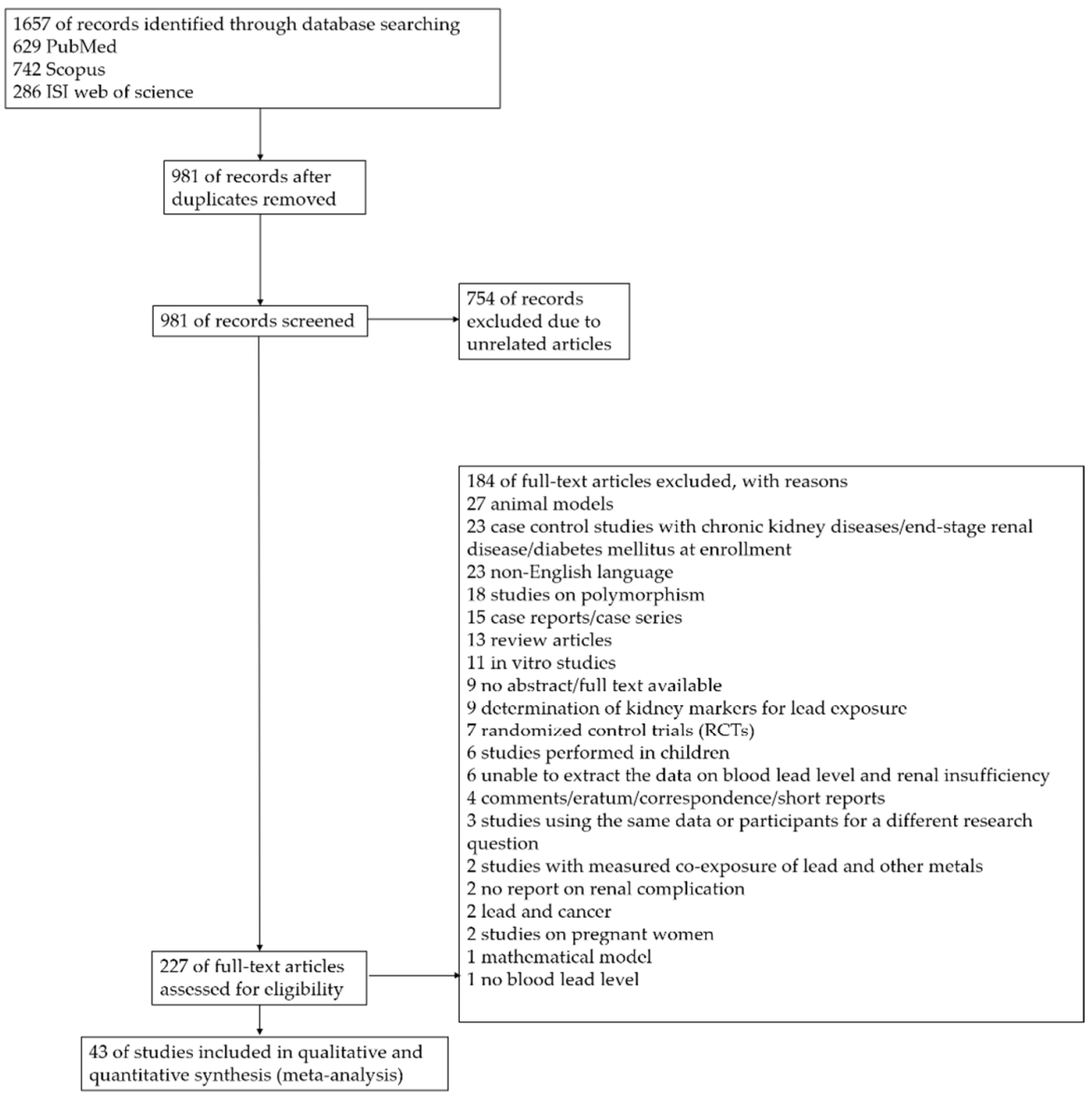

Figure 1. Study flow diagram.

\subsection{Quality of the Included Studies}

The quality of the included studies is shown in Table S2. Seventeen studies were highquality studies, as BLL was reported in both the exposed and non-exposed participants. However, the rest of the included studies were low-quality studies, as they did not enroll a control group. Low-quality studies were included in the present study to analyze the pooled mean BLL.

\subsection{Pooled Mean Blood Lead Level (BLL) among Exposed Participants}

The pooled mean BLL was estimated from all 43 studies [3,4,7,11,13,15-17,19,20,25,29-60] as all 43 studies reported the mean BLL of exposed participants (Figure 2). Among all the participants, the pooled mean BLL was sub-grouped into high mean BLL (BLL > $30 \mu \mathrm{g} / \mathrm{dL}$ ), moderate mean BLL (BLL = 20-30 $\mu \mathrm{g} / \mathrm{dL}$ ), and low mean BLL (BLL < $20 \mu \mathrm{g} / \mathrm{dL})$. Subgroup analysis demonstrated that the pooled mean BLL in the participants with a high mean BLL was $42.41 \mu \mathrm{g} / \mathrm{dL}$ (95\% CI: 42.14-42.67, $\mathrm{I}^{2}$ : 99.1\%), whereas the pooled mean BLL in the participants with moderate and low mean BLL was $22.18 \mu \mathrm{g} / \mathrm{dL}$ (95\% CI: 21.68-22.68, $\mathrm{I}^{2}$ : $60.4 \%$ ) and $2.9 \mu \mathrm{g} / \mathrm{dL}$ (95\% CI: 2.9-2.9, $\mathrm{I}^{2}: 100 \%$ ), respectively. The characteristics of the exposed participants divided into three groups are shown in Table 2. 
Table 1. Characteristics of the included studies.

\begin{tabular}{|c|c|c|c|c|c|c|c|c|c|c|c|c|c|c|c|c|}
\hline \multirow[b]{2}{*}{$\begin{array}{l}\text { No. } \\
\text { (Ref) }\end{array}$} & \multirow[b]{2}{*}{$\begin{array}{l}\text { Author, } \\
\text { Year }\end{array}$} & \multirow[b]{2}{*}{$\begin{array}{c}\text { Study } \\
\text { Area } \\
\text { (Years of } \\
\text { the } \\
\text { Survey), } \\
\text { Exposed } \\
\text { Level }\end{array}$} & \multirow[b]{2}{*}{$\begin{array}{l}\text { Study } \\
\text { Design }\end{array}$} & \multirow[b]{2}{*}{$\begin{array}{l}\text { Participants } \\
\text { (Exposure and } \\
\text { Control } \\
\text { Groups) }\end{array}$} & \multicolumn{6}{|c|}{ Lead Exposure Group } & \multicolumn{6}{|c|}{ Non-Exposed Group } \\
\hline & & & & & $\begin{array}{c}\text { Mean/ } \\
\text { Median } \\
\text { Age, Male } \\
(\%)\end{array}$ & $\begin{array}{c}\text { BLL } \\
\text { Levels } \\
\text { ( } \mu \mathrm{g} / \mathrm{dL}), \\
\text { Duration } \\
\text { of } \\
\text { Exposure } \\
\text { (Years) }\end{array}$ & $\begin{array}{c}\text { BUN } \\
(\mathrm{mg} / \mathrm{dL})\end{array}$ & $\begin{array}{c}\text { Creatinine } \\
(\mathrm{mg} / \mathrm{dL}), \\
\text { Creati- } \\
\text { nine } \\
\text { Clearance } \\
(\mathrm{mL} / \mathrm{min} / \\
\left.1.72 \mathrm{~m}^{2}\right)\end{array}$ & $\begin{array}{l}\text { Uric Acid } \\
\text { (mg/dL) }\end{array}$ & $\begin{array}{l}\text { Renal } \\
\text { Insuffi- } \\
\text { ciency } \\
(\mathbf{n}, \%)\end{array}$ & $\begin{array}{c}\text { Age, Male } \\
(\%)\end{array}$ & $\begin{array}{c}\text { BLL } \\
\text { Levels } \\
\text { ( } \mu \mathrm{g} / \mathrm{dL}), \\
\text { Duration } \\
\text { of } \\
\text { Exposure } \\
\text { (Years) }\end{array}$ & $\begin{array}{c}\text { BUN } \\
(\mathrm{mg} / \mathrm{dL})\end{array}$ & $\begin{array}{c}\text { Creatinine } \\
\text { (mg/dL), } \\
\text { Creati- } \\
\text { nine } \\
\text { Clearance } \\
(\mathrm{mL} / \mathrm{min} / \\
\left.1.72 \mathrm{~m}^{2}\right)\end{array}$ & $\begin{array}{l}\text { Uric Acid } \\
\text { (mg/dL) }\end{array}$ & $\begin{array}{l}\text { Renal } \\
\text { Insuffi- } \\
\text { ciency } \\
(n, \%)\end{array}$ \\
\hline $\begin{array}{c}1 . \\
{[15]}\end{array}$ & $\begin{array}{c}\text { Alasia } \\
\text { et al., } 2010\end{array}$ & Nigeria & $\begin{array}{l}\text { Cross- } \\
\text { sectional } \\
\text { study }\end{array}$ & $\begin{array}{c}\text { Study group } \\
\text { (190); welding } \\
\text { and metal (42), } \\
\text { paint and } \\
\text { pigment (38), } \\
\text { radiator } \\
\text { repairer (37), } \\
\text { battery } \\
\text { workers (37), } \\
\text { petrol (36) } \\
\text { Control group } \\
\text { (80); hospital } \\
\text { workers (80) }\end{array}$ & $\begin{array}{c}\text { NS, } \\
151 / 190 \\
(79.5 \%)\end{array}$ & $\begin{array}{c}50.37 \pm \\
24.58,11.9 \\
\quad \pm 9.3\end{array}$ & $8.6 \pm 2.3$ & $\begin{array}{c}1.0 \pm 0.2 \\
98.9 \pm \\
21.3\end{array}$ & $4.6 \pm 1.2$ & & $58 / 80$ (73) & $\begin{array}{c}41.40 \pm \\
26.9,8.0 \pm \\
7.3\end{array}$ & $7.6 \pm 2.4$ & $\begin{array}{c}0.9 \pm 0.2 \\
108.2 \pm \\
25.2\end{array}$ & $3.9 \pm 1.1$ & \\
\hline $\begin{array}{c}2 . \\
{[29]}\end{array}$ & $\begin{array}{l}\text { Buser } \\
\text { et al., } 2016\end{array}$ & $\begin{array}{l}\text { USA } \\
(2007- \\
2008, \\
2009-2010, \\
\text { and 2011- } \\
2012)\end{array}$ & $\begin{array}{l}\text { Cross- } \\
\text { sectional } \\
\text { study }\end{array}$ & $\begin{array}{l}\text { NHANES } \\
(4875)\end{array}$ & $\begin{array}{c}\text { NS, } \\
2481 / 4875 \\
(50.9 \%)\end{array}$ & $\begin{array}{c}1.58 \\
(1.49-1.67) \\
\text { or } 1.58 \pm \\
0.21\end{array}$ & & $\begin{array}{c}0.85 \pm \\
0.00(4785) \\
91.95 \pm \\
0.58\end{array}$ & & & & & & & & \\
\hline $\begin{array}{c}3 . \\
{[30]}\end{array}$ & $\begin{array}{l}\text { Chen } \\
\text { et al., } 2019\end{array}$ & China & $\begin{array}{l}\text { Cross- } \\
\text { sectional } \\
\text { study }\end{array}$ & $\begin{array}{c}\text { Polluted area } \\
(174), \\
\text { non-exposed } \\
\text { area (157) }\end{array}$ & $\begin{array}{c}\text { Mean } 58.7 \\
(26-80) \\
52 / 164 \\
(31.7 \%)\end{array}$ & $\begin{array}{c}13.1 \\
(8.36-20.6) \\
\text { or } 13.8 \pm \\
3.53\end{array}$ & & $\begin{array}{c}0.79 \\
(0.7-0.95) \\
\text { or } 0.81 \pm \\
0.22,94.7 \\
(79.0- \\
107.9) \text { or } \\
94.1 \pm \\
8.34\end{array}$ & & & $\begin{array}{c}56(25-80) \\
59 / 157\end{array}$ & $\begin{array}{c}7.44 \\
(5.44-11.3) \\
\text { or } 7.91 \pm \\
1.71\end{array}$ & & $\begin{array}{c}0.77 \\
(0.69-0.88) \\
\text { or } 0.78 \pm \\
0.21,102.2 \\
(91.2- \\
112.7) \text { or } \\
102.1 \pm \\
6.21\end{array}$ & & \\
\hline $\begin{array}{c}4 . \\
{[31]}\end{array}$ & $\begin{array}{l}\text { Chung } \\
\text { et al., } 2013\end{array}$ & $\begin{array}{c}\text { The } \\
\text { Republic } \\
\text { of Korea } \\
\text { (2007- } \\
2009)\end{array}$ & $\begin{array}{l}\text { Cross- } \\
\text { sectional } \\
\text { study }\end{array}$ & $\begin{array}{l}\text { The Korea } \\
\text { National } \\
\text { Health and } \\
\text { Nutrition } \\
\text { Examination } \\
\text { Survey } \\
\text { (KNHANES) } \\
\text { nationally } \\
\text { representative } \\
\text { survey (2005) }\end{array}$ & $\begin{array}{c}\text { Mean } 46 \\
\text { (20-87), } \\
\text { male } \\
49.8 \%\end{array}$ & $\begin{array}{c}2.5 \\
\text { eGFR }<60 \\
(83) 2.92 \pm \\
0.13, \text { eGFR } \\
\geq 60 \\
(1922) 2.53 \\
\pm 0.03\end{array}$ & & $\begin{array}{l}\text { GFR: } 90.0 \\
\quad \pm 0.7\end{array}$ & & & & & & & & \\
\hline $\begin{array}{c}5 . \\
{[16]}\end{array}$ & $\begin{array}{l}\text { de Pinto } \\
\text { Almeida } \\
\text { et al., 1987 }\end{array}$ & Brazil & $\begin{array}{l}\text { Cross- } \\
\text { sectional } \\
\text { study }\end{array}$ & $\begin{array}{l}\text { Lead workers } \\
\text { (52), reference } \\
\text { (44) }\end{array}$ & $\begin{array}{c}44.9 \pm 9.54 \\
\text { NS }\end{array}$ & $64.1 \pm 16.3$ & & $\begin{array}{c}1.23 \pm \\
0.34\end{array}$ & $6.6 \pm 1.7$ & $17 / 52$ & $43.4 \pm 8.9$ & $25.5 \pm 4.4$ & & $\begin{array}{c}1.10 \pm \\
0.20\end{array}$ & $4.7 \pm 1.2$ & $1 / 44$ \\
\hline
\end{tabular}


Table 1. Cont.

\begin{tabular}{|c|c|c|c|c|c|c|c|c|c|c|c|c|c|c|c|c|}
\hline \multirow[b]{2}{*}{$\begin{array}{l}\text { No. } \\
\text { (Ref) }\end{array}$} & \multirow[b]{2}{*}{$\begin{array}{l}\text { Author, } \\
\text { Year }\end{array}$} & \multirow[b]{2}{*}{$\begin{array}{c}\text { Study } \\
\text { Area } \\
\text { (Years of } \\
\text { the } \\
\text { Survey), } \\
\text { Exposed } \\
\text { Level }\end{array}$} & \multirow[b]{2}{*}{$\begin{array}{l}\text { Study } \\
\text { Design }\end{array}$} & \multirow[b]{2}{*}{$\begin{array}{l}\text { Participants } \\
\text { (Exposure and } \\
\text { Control } \\
\text { Groups) }\end{array}$} & \multicolumn{6}{|c|}{ Lead Exposure Group } & \multicolumn{6}{|c|}{ Non-Exposed Group } \\
\hline & & & & & $\begin{array}{c}\text { Mean/ } \\
\text { Median } \\
\text { Age, Male } \\
\text { (\%) }\end{array}$ & $\begin{array}{c}\text { BLL } \\
\text { Levels } \\
\text { ( } \mu \mathrm{g} / \mathrm{dL}), \\
\text { Duration } \\
\text { of } \\
\text { Exposure } \\
\text { (Years) } \\
\end{array}$ & $\begin{array}{c}\text { BUN } \\
\text { (mg/dL) }\end{array}$ & $\begin{array}{c}\text { Creatinine } \\
\text { (mg/dL), } \\
\text { Creati- } \\
\text { nine } \\
\text { Clearance } \\
\left(\mathrm{mL} / \mathrm{min}^{2} /\right. \\
\left.1.72 \mathrm{~m}^{2}\right) \\
\end{array}$ & $\begin{array}{l}\text { Uric Acid } \\
\text { (mg/dL) }\end{array}$ & $\begin{array}{l}\text { Renal } \\
\text { Insuffi- } \\
\text { ciency } \\
(n, \%)\end{array}$ & $\underset{(\%)}{\text { Age, Male }}$ & $\begin{array}{c}\text { BLL } \\
\text { Levels } \\
\text { ( } \mu \mathrm{g} / \mathrm{dL}), \\
\text { Duration } \\
\text { of } \\
\text { Exposure } \\
\text { (Years) } \\
\end{array}$ & $\begin{array}{c}\text { BUN } \\
\text { (mg/dL) }\end{array}$ & $\begin{array}{c}\text { Creatinine } \\
\text { (mg/dL), } \\
\text { Creati- } \\
\text { nine } \\
\text { Clearance } \\
\left(\mathrm{mL} / \mathrm{min}^{2} /\right. \\
\left.1.72 \mathrm{~m}^{2}\right)\end{array}$ & $\begin{array}{l}\text { Uric Acid } \\
\text { (mg/dL) }\end{array}$ & $\begin{array}{l}\text { Renal } \\
\text { Insuffi- } \\
\text { ciency } \\
(\mathbf{n}, \%)\end{array}$ \\
\hline $\begin{array}{c}6 . \\
{[32]}\end{array}$ & $\begin{array}{l}\text { Dioka } \\
\text { et al., } 2004\end{array}$ & Nigeria & $\begin{array}{l}\text { Cross- } \\
\text { sectional } \\
\text { study }\end{array}$ & $\begin{array}{c}\text { Exposed } \\
\text { subjects (25); } \\
\text { auto } \\
\text { mechanics (18), } \\
\text { battery } \\
\text { chargers (5), } \\
\text { welders (2) } \\
\text { unexposed } \\
\text { subjects (25); } \\
\text { graduate } \\
\text { students }\end{array}$ & $\begin{array}{c}39 \pm 8.47 \\
\text { male } \\
50 / 50 \\
(100 \%)\end{array}$ & $\begin{array}{c}59.6 \pm \\
15.9\end{array}$ & $\begin{array}{c}58.8 \pm \\
13.6\end{array}$ & $1.12 \pm 0.2$ & $\begin{array}{l}4.04 \pm \\
1.39\end{array}$ & & $\begin{array}{c}\text { Age } \\
\text { matched }\end{array}$ & $35 \pm 7.9$ & $\begin{array}{c}55.4 \pm \\
6.79\end{array}$ & $1.15 \pm 0.2$ & $\begin{array}{c}2.58 \pm \\
1.19\end{array}$ & \\
\hline $\begin{array}{c}7 . \\
{[13]}\end{array}$ & $\begin{array}{l}\text { Ehrlich } \\
\text { et al., } 1998\end{array}$ & $\begin{array}{l}\text { South } \\
\text { Africa }\end{array}$ & $\begin{array}{l}\text { Cross- } \\
\text { sectional } \\
\text { study }\end{array}$ & $\begin{array}{c}\text { Battery making } \\
\text { workforce } \\
(\mathrm{n}=382)\end{array}$ & $\begin{array}{c}\text { Mean } 41.2 \\
\text { (8.3), NS }\end{array}$ & $\begin{array}{c}53.5 \pm \\
12.7,11.6 \\
\pm 6.8\end{array}$ & $5.6 \pm 1.5$ & $\begin{array}{c}1.13 \pm \\
0.18\end{array}$ & & $\begin{array}{c}\text { BLL 23-50 } \\
\mu \mathrm{g} / \mathrm{dL} \\
(160), \\
51-60 \\
(115), \\
61-110 \\
(101)\end{array}$ & & & & & & \\
\hline
\end{tabular}


Table 1. Cont.

\begin{tabular}{|c|c|c|c|c|c|c|c|c|c|c|c|c|c|c|c|c|}
\hline \multirow[b]{2}{*}{$\begin{array}{l}\text { No. } \\
\text { (Ref) }\end{array}$} & \multirow[b]{2}{*}{$\begin{array}{l}\text { Author, } \\
\text { Year }\end{array}$} & \multirow[b]{2}{*}{$\begin{array}{c}\text { Study } \\
\text { Area } \\
\text { (Years of } \\
\text { the } \\
\text { Survey), } \\
\text { Exposed } \\
\text { Level }\end{array}$} & \multirow[b]{2}{*}{$\begin{array}{c}\text { Study } \\
\text { Design }\end{array}$} & \multirow[b]{2}{*}{$\begin{array}{l}\text { Participants } \\
\text { (Exposure and } \\
\text { Control } \\
\text { Groups) }\end{array}$} & \multicolumn{6}{|c|}{ Lead Exposure Group } & \multicolumn{6}{|c|}{ Non-Exposed Group } \\
\hline & & & & & $\begin{array}{c}\text { Mean/ } \\
\text { Median } \\
\text { Age, Male } \\
\mathbf{( \% )}\end{array}$ & $\begin{array}{c}\text { BLL } \\
\text { Levels } \\
\text { ( } \mu \mathrm{g} / \mathrm{dL}), \\
\text { Duration } \\
\text { of } \\
\text { Exposure } \\
\text { (Years) }\end{array}$ & $\begin{array}{l}\text { BUN } \\
(\mathrm{mg} / \mathrm{dL})\end{array}$ & $\begin{array}{c}\text { Creatinine } \\
\text { (mg/dL), } \\
\text { Creati- } \\
\text { nine } \\
\text { Clearance } \\
\left(\mathrm{mL} / \mathrm{min}^{2} /\right. \\
\left.1.72 \mathrm{~m}^{2}\right)\end{array}$ & $\begin{array}{l}\text { Uric Acid } \\
\text { (mg/dL) }\end{array}$ & $\begin{array}{l}\text { Renal } \\
\text { Insuffi- } \\
\text { ciency } \\
(\mathbf{n}, \%)\end{array}$ & $\begin{array}{c}\text { Age, Male } \\
(\%)\end{array}$ & $\begin{array}{c}\text { BLL } \\
\text { Levels } \\
\text { ( } \mu \mathrm{g} / \mathrm{dL}), \\
\text { Duration } \\
\text { of } \\
\text { Exposure } \\
\text { (Years) }\end{array}$ & $\begin{array}{c}\text { BUN } \\
(\mathrm{mg} / \mathrm{dL})\end{array}$ & $\begin{array}{c}\text { Creatinine } \\
\text { (mg/dL), } \\
\text { Creati- } \\
\text { nine } \\
\text { Clearance } \\
(\mathrm{mL} / \mathrm{min} / \\
\left.1.72 \mathrm{~m}^{2}\right)\end{array}$ & $\begin{array}{l}\text { Uric Acid } \\
\text { (mg/dL) }\end{array}$ & $\begin{array}{l}\text { Renal } \\
\text { Insuffi- } \\
\text { ciency } \\
(\mathrm{n}, \%)\end{array}$ \\
\hline $\begin{array}{c}9 . \\
{[34]}\end{array}$ & $\begin{array}{l}\text { Gerhardsson } \\
\text { et al., } 1998\end{array}$ & Sweden & $\begin{array}{l}\text { Cross- } \\
\text { sectional } \\
\text { study }\end{array}$ & $\begin{array}{c}\text { Smelter } \\
\text { workers (22); } \\
\text { active workers } \\
\text { (11), retired } \\
\text { workers (11) } \\
\text { referents (11); } \\
\text { nearby } \\
\text { machine-shop }\end{array}$ & $\begin{array}{c}\text { NS, } 22 / 22 \\
(100 \%)\end{array}$ & $\begin{array}{c}25.3 \pm \\
11.4 \\
\text { Active } \\
\text { workers } \\
31.1 \\
(7.67-49.7) \\
\text { or } 29.8 \pm \\
12.9, \\
\text { Retired } \\
\text { workers } \\
19.3 \\
(11.2-33.2) \\
\text { or } 20.7 \pm \\
7.67\end{array}$ & & & & & & $\begin{array}{c}4.14 \\
(2.07-7.05) \\
\text { or } 4.35 \pm \\
1.45\end{array}$ & & & & \\
\hline $\begin{array}{l}10 . \\
{[35]}\end{array}$ & $\begin{array}{l}\text { Gerhardsson } \\
\text { et al., } 1992\end{array}$ & Sweden & $\begin{array}{l}\text { Cross- } \\
\text { sectional } \\
\text { study }\end{array}$ & $\begin{array}{c}\text { Smelter } \\
\text { workers (100); } \\
\text { active workers } \\
\text { (70), retired } \\
\text { workers (30) } \\
\text { referents (41); } \\
\text { active truck } \\
\text { assembly } \\
\text { workers (31), } \\
\text { retired truck } \\
\text { assembly } \\
\text { workers (10) }\end{array}$ & $\begin{array}{c}\text { Active } \\
\text { workers } \\
37.4 \pm \\
12-6), \text { NS } \\
\text { Retired } \\
\text { workers } \\
67.9 \pm 47 \\
\text { NS }\end{array}$ & $\begin{array}{c}23.7 \pm \\
13.5 \\
\text { Active } \\
\text { workers } \\
31.91 \\
(4.97- \\
47.45) \text { or } \\
29.1 \pm \\
12.3, \\
\text { Retired } \\
\text { workers } \\
9.95(3.32- \\
20.93) \text { or } \\
11 \pm 5.1 \\
\text { Duration } \\
\text { of job: } 19.8 \\
\pm 12.2 \\
\text { Active } \\
\text { workers } \\
14.3 \pm 9.7 \\
\text { Retired } \\
\text { workers } \\
\text { (32.6 } \pm \\
6.3)\end{array}$ & & $\begin{array}{c}1.02 \pm \\
0.26 \\
\text { Active } \\
\text { workers } \\
1.02 \\
(0.75-1.32) \\
\text { or 1.03 } \pm \\
0.26, \\
\text { Retired } \\
\text { workers } \\
1.05 \\
(0.71-1.23) \\
\text { or } 1.11 \pm \\
0.25 \\
\text { CRCL } \\
102.4 \pm \\
43.2 ; \\
\text { Active } \\
\text { workers } \\
105 \\
(26-180) \\
\text { or } 104 \pm \\
44.5, \\
\text { Retired } \\
\text { workers } \\
87 \\
(40-180) \\
\text { or } 98.5 \pm \\
40.4\end{array}$ & & & & $\begin{array}{c}5.54 \pm \\
3.03 \\
\text { Active } \\
\text { workers } \\
4.14(1.66 \\
-12.4) \text { or } \\
5.59 \pm \\
3.12, \\
\text { Retired } \\
\text { workers } \\
3.52 \\
(2.28-12.2) \\
\text { or } 5.38 \pm \\
2.88\end{array}$ & & $\begin{array}{c}1.02 \pm \\
0.22 \\
\text { Active } \\
\text { workers } \\
1.0 \\
(0.84-1.15) \\
\text { or } 1 \pm \\
0.22, \\
\text { Retired } \\
\text { workers } \\
1.04 \\
(0.89-1.32) \\
\text { or } 1.07 \pm \\
0.24 \\
\text { CRCL: } \\
\text { Active } \\
\text { workers } \\
105 \\
(26-180) \\
\text { mmol/dL, } \\
\text { Retired } \\
\text { workers } \\
87 \\
(40-180)\end{array}$ & & \\
\hline
\end{tabular}


Table 1. Cont.

\begin{tabular}{|c|c|c|c|c|c|c|c|c|c|c|c|c|c|c|c|c|}
\hline \multirow[b]{2}{*}{$\begin{array}{l}\text { No. } \\
\text { (Ref) }\end{array}$} & \multirow[b]{2}{*}{$\begin{array}{l}\text { Author, } \\
\text { Year }\end{array}$} & \multirow[b]{2}{*}{$\begin{array}{c}\text { Study } \\
\text { Area } \\
\text { (Years of } \\
\text { the } \\
\text { Survey), } \\
\text { Exposed } \\
\text { Level }\end{array}$} & \multirow[b]{2}{*}{$\begin{array}{l}\text { Study } \\
\text { Design }\end{array}$} & \multirow[b]{2}{*}{$\begin{array}{l}\text { Participants } \\
\text { (Exposure and } \\
\text { Control } \\
\text { Groups) }\end{array}$} & \multicolumn{6}{|c|}{ Lead Exposure Group } & \multicolumn{6}{|c|}{ Non-Exposed Group } \\
\hline & & & & & $\begin{array}{c}\text { Mean/ } \\
\text { Median } \\
\text { Age, Male } \\
\text { (\%) }\end{array}$ & $\begin{array}{c}\text { BLL } \\
\text { Levels } \\
\text { ( } \mu \mathrm{g} / \mathrm{dL}), \\
\text { Duration } \\
\text { of } \\
\text { Exposure } \\
\text { (Years) } \\
\end{array}$ & $\begin{array}{c}\text { BUN } \\
\text { (mg/dL) }\end{array}$ & $\begin{array}{c}\text { Creatinine } \\
\text { (mg/dL), } \\
\text { Creati- } \\
\text { nine } \\
\text { Clearance } \\
\left(\mathrm{mL} / \mathrm{min}^{2} /\right. \\
\left.1.72 \mathrm{~m}^{2}\right) \\
\end{array}$ & $\begin{array}{l}\text { Uric Acid } \\
\text { (mg/dL) }\end{array}$ & $\begin{array}{l}\text { Renal } \\
\text { Insuffi- } \\
\text { ciency } \\
(\mathrm{n}, \%)\end{array}$ & $\underset{(\%)}{\text { Age, Male }}$ & $\begin{array}{c}\text { BLL } \\
\text { Levels } \\
\text { ( } \mu \mathrm{g} / \mathrm{dL}), \\
\text { Duration } \\
\text { of } \\
\text { Exposure } \\
\text { (Years) } \\
\end{array}$ & $\begin{array}{c}\text { BUN } \\
\text { (mg/dL) }\end{array}$ & $\begin{array}{c}\text { Creatinine } \\
\text { (mg/dL), } \\
\text { Creati- } \\
\text { nine } \\
\text { Clearance } \\
(\mathrm{mL} / \mathrm{min} / \\
\left.1.72 \mathrm{~m}^{2}\right) \\
\end{array}$ & $\begin{array}{l}\text { Uric Acid } \\
\text { (mg/dL) }\end{array}$ & $\begin{array}{l}\text { Renal } \\
\text { Insuffi- } \\
\text { ciency } \\
(\mathbf{n}, \%)\end{array}$ \\
\hline $\begin{array}{l}11 . \\
{[36]}\end{array}$ & $\begin{array}{l}\text { Goswami } \\
\text { et al., } 2001\end{array}$ & India & $\begin{array}{l}\text { Cross- } \\
\text { sectional } \\
\text { study }\end{array}$ & $\begin{array}{c}372 \\
\text { Battery }(63 \%), \\
\text { pigments } \\
(12.8 \%), \\
\text { rolled/extruded } \\
(7.7 \%), \text { cable } \\
\text { sheeting }(4.5 \%), \\
\text { gas add }(2.2 \%), \\
\text { others }(9.9 \%)\end{array}$ & $\begin{array}{c}36.2 \pm 7.8 \\
372 / 372 \\
(100 \%)\end{array}$ & $\begin{array}{c}21.2 \pm \\
13.9 \\
\text { Group A } \\
\text { (185): } 12.6 \\
\pm 3.9 \\
\text { Group } \\
\text { (63): } 17.9 \\
\pm 2.1 \\
\text { Group C } \\
\text { (99): } 29.8 \\
\pm 9.6 \\
\text { Group D } \\
\text { (25): } 58.7 \\
\pm 11.3\end{array}$ & $\begin{array}{c}\text { Group A: } \\
13 \pm 8 \\
\text { Group B: } \\
26 \pm 7 \\
\text { Group C: } \\
35 \pm 13 \\
\text { Group D: } \\
51 \pm 12\end{array}$ & $\begin{array}{c}1.1 \pm 0.89 \\
\text { Group A: } \\
0.9 \pm 0.6, \\
\text { Group B: } \\
1.2 \pm 0.9, \\
\text { Group C: } \\
1.3 \pm 1.1 \\
\text { Group D: } \\
1.5 \pm 1.3 \\
\text { eGFR } \\
\text { Group A: } \\
141 \pm 16, \\
\text { Group B: } \\
86 \pm 22, \\
\text { Group C: } \\
55 \pm 24, \\
\text { Group D: } \\
33 \pm 28\end{array}$ & & $\begin{array}{l}25 \text { with } \\
\text { advanced } \\
\text { renal } \\
\text { diseases }\end{array}$ & & & & & & \\
\hline $\begin{array}{l}12 . \\
{[3]}\end{array}$ & $\begin{array}{c}\text { Harar } \\
\text { et al., } 2018\end{array}$ & $\begin{array}{l}\text { Sweden } \\
(2007- \\
2012)\end{array}$ & $\begin{array}{l}\text { Cohort } \\
\text { study }\end{array}$ & $\begin{array}{c}4341 \\
\text { individuals } \\
\text { enrolled and } \\
2567 \\
\text { individuals } \\
\text { subsequently } \\
\text { followed up }\end{array}$ & $\begin{array}{c}\text { Based line } \\
57 \pm 5.9 \\
1729 / \\
4341 \\
(39.8 \%)\end{array}$ & $\begin{array}{c}2.5 \\
(0.15-25.8) \\
\text { or } 7.74 \pm \\
7.41\end{array}$ & & $\begin{array}{c}\text { eGFR: } \\
\text { based line } \\
\text { (4272); } 76 \\
\pm 14 \\
\text { followed } \\
\text { up (2735); } \\
70 \pm 15\end{array}$ & & $\begin{array}{c}185 \\
\text { chronic } \\
\text { kidney } \\
\text { diseases }\end{array}$ & & & & & & \\
\hline $\begin{array}{l}13 . \\
{[37]}\end{array}$ & $\begin{array}{l}\text { Hernandez- } \\
\text { Serrato } \\
\text { et al., } 2006\end{array}$ & Mexico & $\begin{array}{l}\text { Cross- } \\
\text { sectional } \\
\text { study }\end{array}$ & $\begin{array}{l}\text { Exposed group } \\
\text { (413): glazed } \\
\text { pottery used, } \\
\text { exposure } \\
\text { occupation }\end{array}$ & $\begin{array}{c}37.27 \pm \\
16.3 \\
156 / 413 \\
(37.8 \%)\end{array}$ & $\begin{array}{c}43.57 \pm \\
14.5\end{array}$ & $\begin{array}{c}33.17 \pm \\
11.7\end{array}$ & $\begin{array}{c}0.97 \pm \\
0.23\end{array}$ & $\begin{array}{c}6.47 \pm \\
1.90\end{array}$ & $\begin{array}{c}\mathrm{BLL} \geq 40 \\
\mathrm{mg} / \mathrm{dL} \\
(8 / 244) \\
<40 \\
\mathrm{mg} / \mathrm{dL} \\
(4 / 169)\end{array}$ & & & & & & \\
\hline
\end{tabular}


Table 1. Cont.

\begin{tabular}{|c|c|c|c|c|c|c|c|c|c|c|c|c|c|c|c|c|}
\hline \multirow[b]{2}{*}{$\begin{array}{c}\text { No. } \\
\text { (Ref) }\end{array}$} & \multirow[b]{2}{*}{$\begin{array}{l}\text { Author, } \\
\text { Year }\end{array}$} & \multirow[b]{2}{*}{$\begin{array}{c}\text { Study } \\
\text { Area } \\
\text { (Years of } \\
\text { the } \\
\text { Survey), } \\
\text { Exposed } \\
\text { Level }\end{array}$} & \multirow[b]{2}{*}{$\begin{array}{c}\text { Study } \\
\text { Design }\end{array}$} & \multirow[b]{2}{*}{$\begin{array}{c}\text { Participants } \\
\text { (Exposure and } \\
\text { Control } \\
\text { Groups) }\end{array}$} & \multicolumn{6}{|c|}{ Lead Exposure Group } & \multicolumn{6}{|c|}{ Non-Exposed Group } \\
\hline & & & & & $\begin{array}{c}\text { Mean/ } \\
\text { Median } \\
\text { Age, Male } \\
\text { (\%) }\end{array}$ & $\begin{array}{c}\text { BLL } \\
\text { Levels } \\
\text { ( } \mu \text { g/dL), } \\
\text { Duration } \\
\text { of } \\
\text { Exposure } \\
\text { (Years) }\end{array}$ & $\underset{(\mathrm{mg} / \mathrm{dL})}{\mathrm{BUN}}$ & $\begin{array}{c}\text { Creatinine } \\
(\mathrm{mg} / \mathrm{dL}), \\
\text { Creati- } \\
\text { nine } \\
\text { Clearance } \\
(\mathrm{mL} / \mathrm{min} / \\
\left.1.72 \mathrm{~m}^{2}\right)\end{array}$ & $\begin{array}{l}\text { Uric Acid } \\
\text { (mg/dL) }\end{array}$ & $\begin{array}{l}\text { Renal } \\
\text { Insuffi- } \\
\text { ciency } \\
(\mathbf{n}, \%)\end{array}$ & $\begin{array}{c}\text { Age, Male } \\
(\%)\end{array}$ & $\begin{array}{c}\text { BLL } \\
\text { Levels } \\
\text { ( } \mu \mathrm{g} / \mathrm{dL}), \\
\text { Duration } \\
\text { of } \\
\begin{array}{c}\text { Exposure } \\
\text { (Years) }\end{array}\end{array}$ & $\underset{(\mathrm{mg} / \mathrm{dL})}{\mathrm{BUN}}$ & $\begin{array}{c}\text { Creatinine } \\
(\mathrm{mg} / \mathrm{dL}), \\
\text { Creati- } \\
\text { nine } \\
\text { Clearance } \\
(\mathrm{mL} / \mathrm{min} / \\
\left.1.72 \mathrm{~m}^{2}\right)\end{array}$ & $\begin{array}{l}\text { Uric Acid } \\
\text { (mg/dL) }\end{array}$ & $\begin{array}{l}\text { Renal } \\
\text { Insuffi- } \\
\text { ciency } \\
(n, \%)\end{array}$ \\
\hline $\begin{array}{c}14 . \\
{[38]}\end{array}$ & $\begin{array}{l}\text { Jain RB, } \\
2019\end{array}$ & $\begin{array}{c}\text { USA } \\
(2003- \\
2014)\end{array}$ & $\begin{array}{l}\text { Retrospective } \\
\text { study }\end{array}$ & $\begin{array}{c}\text { The data from } \\
\text { National } \\
\text { Health and } \\
\text { Nutritional } \\
\text { Examination } \\
\text { Survey } \\
\text { (NHANES): } \\
\text { 9822 } \\
\text { GF-1: } 5710 \\
\text { GF-2: } 3263 \\
\text { GF-3A: } 563 \\
\text { GF-3B/4: } 286\end{array}$ & $\begin{array}{c}\geq 20 \\
5044 / \\
9822 \\
(51.4 \%)\end{array}$ & $\begin{array}{c}1.24 \pm \\
0.32 \\
\text { Glomerular } \\
\text { function } \\
\text { (GF) } \\
\text { GF-1: } 1.05 \\
(1.02-1.09) \\
\text { or } 1.05 \pm \\
0.21, \mathrm{GF}-2 \text { : } \\
1.42 \\
(1.37-1.47) \\
\text { or } 1.42 \pm \\
0.2, \\
\text { GF-3A: } \\
1.74 \\
(1.63-1.87) \\
\text { or } 1.75 \pm \\
0.22, \\
\text { GF-3B } / 4: \\
1.87 \\
(1.70-2.05) \\
\text { or } 1.87 \pm \\
0.23\end{array}$ & & & & & & & & & & \\
\hline
\end{tabular}


Table 1. Cont.

\begin{tabular}{|c|c|c|c|c|c|c|c|c|c|c|c|c|c|c|c|c|}
\hline \multirow[b]{2}{*}{$\begin{array}{l}\text { No. } \\
\text { (Ref) }\end{array}$} & \multirow[b]{2}{*}{$\begin{array}{l}\text { Author, } \\
\text { Year }\end{array}$} & \multirow[b]{2}{*}{$\begin{array}{l}\text { Study } \\
\text { Area } \\
\text { (Years of } \\
\text { the } \\
\text { Survey), } \\
\text { Exposed } \\
\text { Level }\end{array}$} & \multirow[b]{2}{*}{$\begin{array}{c}\text { Study } \\
\text { Design }\end{array}$} & \multirow[b]{2}{*}{$\begin{array}{l}\text { Participants } \\
\text { (Exposure and } \\
\text { Control } \\
\text { Groups) }\end{array}$} & \multicolumn{6}{|c|}{ Lead Exposure Group } & \multicolumn{6}{|c|}{ Non-Exposed Group } \\
\hline & & & & & $\begin{array}{c}\text { Mean/ } \\
\text { Median } \\
\text { Age, Male } \\
\text { (\%) }\end{array}$ & $\begin{array}{c}\text { BLL } \\
\text { Levels } \\
\text { ( } \mu \mathrm{g} / \mathrm{dL}), \\
\text { Duration } \\
\text { of } \\
\text { Exposure } \\
\text { (Years) }\end{array}$ & $\begin{array}{c}\text { BUN } \\
(\mathrm{mg} / \mathrm{dL})\end{array}$ & 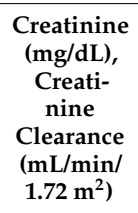 & $\begin{array}{l}\text { Uric Acid } \\
\text { (mg/dL) }\end{array}$ & $\begin{array}{l}\text { Renal } \\
\text { Insuffi- } \\
\text { ciency } \\
(n, \%)\end{array}$ & $\begin{array}{c}\text { Age, Male } \\
(\%)\end{array}$ & $\begin{array}{c}\text { BLL } \\
\text { Levels } \\
\text { ( } \mu \mathrm{g} / \mathrm{dL}), \\
\text { Duration } \\
\text { of } \\
\begin{array}{c}\text { Exposure } \\
\text { (Years) }\end{array}\end{array}$ & $\begin{array}{c}\text { BUN } \\
(\mathrm{mg} / \mathrm{dL})\end{array}$ & 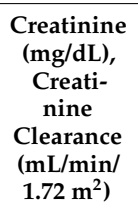 & $\begin{array}{l}\text { Uric Acid } \\
\text { (mg/dL) }\end{array}$ & $\begin{array}{l}\text { Renal } \\
\text { Insuffi- } \\
\text { ciency } \\
(\mathbf{n}, \%)\end{array}$ \\
\hline $\begin{array}{l}15 . \\
{[39]}\end{array}$ & $\begin{array}{c}\text { Jung et al., } \\
1998\end{array}$ & $\begin{array}{l}\text { Republic } \\
\text { of Korea }\end{array}$ & $\begin{array}{l}\text { Cross- } \\
\text { sectional } \\
\text { study }\end{array}$ & $\begin{array}{c}\text { Lead exposed } \\
\text { workers (75): } \\
\text { secondary lead } \\
\text { smelter } \\
\text { industry (27), } \\
\text { plastic } \\
\text { stabilizer } \\
\text { industry (18), } \\
\text { radiator } \\
\text { manufacturing } \\
\text { industry (30) } \\
\text { control group } \\
\text { (64): male } \\
\text { office workers }\end{array}$ & $\begin{array}{c}41.5 \pm \\
7.67, \\
75 / 75 \\
(100 \%) \\
\text { Highly } \\
\text { exposed } \\
(21): 43.6 \\
\pm 8.3 \\
\pm .3 \\
\text { Moder- } \\
\text { ately } \\
\text { exposed } \\
\text { (20): } 42.3 \\
\pm 8.6, \\
\text { Slightly } \\
\text { exposed } \\
\text { (34): } 39.7 \\
\pm 6.4\end{array}$ & $\begin{array}{c}44.3 \pm \\
21.8 \\
\text { Highly } \\
\text { exposed: } \\
74.6 \pm 7.8 \\
\text { moder- } \\
\text { ately } \\
\text { exposed: } \\
46.5 \pm 5.9, \\
\text { slightly } \\
\text { exposed: } \\
24.3 \pm 2.7 \\
\text { Duration } \\
\text { of } \\
\text { employed: } \\
8.27 \pm \\
4.29 \\
\text { Highly } \\
\text { exposed: } \\
8.5 \pm 3.8 \\
\text { moder- } \\
\text { ately } \\
\text { exposed: } \\
8.3 \pm 6.2, \\
\text { slightly } \\
\text { exposed: } \\
8.1 \pm 3.2\end{array}$ & $\begin{array}{c}15.8 \pm \\
4.54 \\
\text { Highly } \\
\text { exposed: } \\
18 \pm 5.5, \\
\text { moder- } \\
\text { ately } \\
\text { exposed: } \\
15.6 \pm 3.9 \\
\text { slightly } \\
\text { exposed: } \\
14.6 \pm 3.8\end{array}$ & $\begin{array}{c}0.86 \pm \\
0.19 \\
\text { Highly } \\
\text { exposed: } \\
0.9 \pm 0.2 \\
\text { moder- } \\
\text { ately } \\
\text { exposed: } \\
0.8 \pm 0.1 \\
\text { slightly } \\
\text { exposed: } \\
0.8 \pm 0.2\end{array}$ & $\begin{array}{c}5.41 \pm \\
1.43 \\
\text { Highly } \\
\text { exposed: } 6 \\
\pm 1.5 \\
\text { moder- } \\
\text { ately } \\
\text { exposed: } \\
5.1 \pm 1.1 \\
\text { slightly } \\
\text { exposed: } \\
5.2 \pm 1.5\end{array}$ & $\begin{array}{l}\text { Highly } \\
\text { exposed } \\
\text { (2) }\end{array}$ & $\begin{array}{l}44.2 \pm 8.6 \\
\quad(64)\end{array}$ & $\begin{array}{c}7.9 \pm 1.4 \\
\text { duration } \\
\text { of } \\
\text { employed: } \\
8.1 \pm 2.4\end{array}$ & $13 \pm 4$ & $0.9 \pm 0.2$ & $5.6 \pm 1.5$ & 1 \\
\hline $\begin{array}{l}16 . \\
{[40]}\end{array}$ & $\begin{array}{c}\text { Kim et al., } \\
1996\end{array}$ & $\begin{array}{l}\text { USA } \\
(1979- \\
1992)\end{array}$ & $\begin{array}{l}\text { Retrospective } \\
\text { study }\end{array}$ & $\begin{array}{l}459 \text { men } \\
\text { randomly } \\
\text { selected from } \\
\text { the Normative } \\
\text { Aging Study }\end{array}$ & $\begin{array}{c}56.9 \pm 8.3 \\
459 / 459 \\
(100 \%)\end{array}$ & $9.9 \pm 6.1$ & & $\begin{array}{c}1.22 \\
(0.9-1.8) \\
\text { or } 1.29 \pm \\
0.33\end{array}$ & & & & & & & & \\
\hline $\begin{array}{l}17 . \\
{[7]}\end{array}$ & $\begin{array}{l}\text { Kshirsagar } \\
\text { et al., } 2020\end{array}$ & India & $\begin{array}{l}\text { Cross- } \\
\text { sectional } \\
\text { study }\end{array}$ & $\begin{array}{l}\text { Spray painters } \\
\text { (42), normal } \\
\text { healthy } \\
\text { subjects (50) }\end{array}$ & $\begin{array}{c}\text { Range } \\
20-50 \text {, NS }\end{array}$ & $\begin{array}{c}30.5 \pm \\
12.2\end{array}$ & $\begin{array}{c}20.5 \pm \\
4.78\end{array}$ & $\begin{array}{c}1.21 \pm \\
0.26\end{array}$ & $6.6 \pm 2$ & & $20-50$ & $\begin{array}{c}5.46 \pm \\
2.58\end{array}$ & $\begin{array}{c}20.5 \pm \\
4.78\end{array}$ & $\begin{array}{c}0.98 \pm \\
0.17\end{array}$ & $\begin{array}{c}5.41 \pm \\
1.03\end{array}$ & \\
\hline $\begin{array}{l}18 . \\
{[41]}\end{array}$ & $\begin{array}{l}\text { Kshirsagar } \\
\text { et al., } 2019\end{array}$ & $\begin{array}{l}\text { India } \\
\text { (2018) }\end{array}$ & $\begin{array}{l}\text { Cross- } \\
\text { sectional } \\
\text { study }\end{array}$ & $\begin{array}{c}\text { Silver jewelry } \\
\text { workers } \\
(42) \\
\text { control group } \\
(50)\end{array}$ & $\begin{array}{c}\text { Range } \\
20-60 \text {, NS }\end{array}$ & $\begin{array}{c}23.23 \pm \\
5.91\end{array}$ & $\begin{array}{c}22.9 \pm \\
5.93\end{array}$ & $\begin{array}{c}1.12 \pm \\
0.17\end{array}$ & $\begin{array}{c}6.39 \pm \\
1.18\end{array}$ & & $20-60$ & $\begin{array}{c}5.46 \pm \\
2.58\end{array}$ & $\begin{array}{c}20.5 \pm \\
4.78\end{array}$ & $\begin{array}{c}0.98 \pm \\
0.17\end{array}$ & $\begin{array}{c}5.41 \pm \\
1.03\end{array}$ & \\
\hline
\end{tabular}


Table 1. Cont.

\begin{tabular}{|c|c|c|c|c|c|c|c|c|c|c|c|c|c|c|c|c|}
\hline \multirow[b]{2}{*}{$\begin{array}{l}\text { No. } \\
\text { (Ref) }\end{array}$} & \multirow[b]{2}{*}{$\begin{array}{l}\text { Author, } \\
\text { Year }\end{array}$} & \multirow[b]{2}{*}{$\begin{array}{c}\text { Study } \\
\text { Area } \\
\text { (Years of } \\
\text { the } \\
\text { Survey), } \\
\text { Exposed } \\
\text { Level }\end{array}$} & \multirow[b]{2}{*}{$\begin{array}{c}\text { Study } \\
\text { Design }\end{array}$} & \multirow[b]{2}{*}{$\begin{array}{l}\text { Participants } \\
\text { (Exposure and } \\
\text { Control } \\
\text { Groups) }\end{array}$} & \multicolumn{6}{|c|}{ Lead Exposure Group } & \multicolumn{6}{|c|}{ Non-Exposed Group } \\
\hline & & & & & $\begin{array}{c}\text { Mean/ } \\
\text { Median } \\
\text { Age, Male } \\
\text { (\%) }\end{array}$ & $\begin{array}{c}\text { BLL } \\
\text { Levels } \\
\text { ( } \mu \mathrm{g} / \mathrm{dL}), \\
\text { Duration } \\
\text { of } \\
\text { Exposure } \\
\text { (Years) } \\
\end{array}$ & $\begin{array}{c}\text { BUN } \\
(\mathrm{mg} / \mathrm{dL})\end{array}$ & $\begin{array}{c}\text { Creatinine } \\
\text { (mg/dL), } \\
\text { Creati- } \\
\text { nine } \\
\text { Clearance } \\
\left(\mathrm{mL} / \mathrm{min}^{2} /\right. \\
\left.1.72 \mathrm{~m}^{2}\right)\end{array}$ & $\begin{array}{l}\text { Uric Acid } \\
\text { (mg/dL) }\end{array}$ & $\begin{array}{l}\text { Renal } \\
\text { Insuffi- } \\
\text { ciency } \\
(\mathbf{n}, \%)\end{array}$ & $\begin{array}{c}\text { Age, Male } \\
(\%)\end{array}$ & $\begin{array}{c}\text { BLL } \\
\text { Levels } \\
\text { ( } \mu \mathrm{g} / \mathrm{dL}), \\
\text { Duration } \\
\text { of } \\
\text { Exposure } \\
\text { (Years) } \\
\end{array}$ & $\begin{array}{c}\text { BUN } \\
(\mathrm{mg} / \mathrm{dL})\end{array}$ & $\begin{array}{c}\text { Creatinine } \\
\text { (mg/dL), } \\
\text { Creati- } \\
\text { nine } \\
\text { Clearance } \\
(\mathrm{mL} / \mathrm{min} / \\
\left.1.72 \mathrm{~m}^{2}\right) \\
\end{array}$ & $\begin{array}{l}\text { Uric Acid } \\
\text { (mg/dL) }\end{array}$ & $\begin{array}{l}\text { Renal } \\
\text { Insuffi- } \\
\text { ciency } \\
(\mathbf{n}, \%)\end{array}$ \\
\hline $\begin{array}{l}19 . \\
{[11]}\end{array}$ & $\begin{array}{l}\text { Lai et al., } \\
2008\end{array}$ & Taiwan & $\begin{array}{l}\text { Cross- } \\
\text { sectional } \\
\text { study }\end{array}$ & $\begin{array}{c}2565 \text { residents: } \\
\text { aboriginals } \\
(1318), \\
\text { nonaboriginals } \\
(1247)\end{array}$ & $>40, \mathrm{NS}$ & $\begin{array}{c}5.3 \pm 1.2 \\
\text { Male } \\
(1008): 5.3 \\
\pm 1.2,5.6 \\
\pm 1.4) \\
\text { female } \\
(1557): 5.3 \\
\pm 1.1,5.4 \\
\pm 1.2\end{array}$ & $\begin{array}{c}\text { Male }(15.4 \\
\pm 4.3,15.5 \\
\pm 4.6) \\
\text { female } \\
(14.9 \pm 4.5 \\
15.7 \pm 5.6)\end{array}$ & $\begin{array}{c}1.1 \pm 0.28 \\
\text { Male }(1.2 \\
\pm 0.3,1.1 \\
\pm 0.4) \\
\text { female } \\
(1.0 \pm 0.2 \\
1.0 \pm 0.5)\end{array}$ & $\begin{array}{c}\text { Male }(6.9 \\
\pm 1.8,8.6 \\
\pm 2.1) \\
\text { female } \\
(5.8 \pm 1.8 \\
7.0 \pm 1.9)\end{array}$ & $\begin{array}{l}\text { Aboriginals } \\
\text { (153), } \\
\text { Nonabo- } \\
\text { riginals } \\
\text { (87) }\end{array}$ & & & & & & \\
\hline $\begin{array}{l}20 . \\
{[25]}\end{array}$ & $\begin{array}{l}\text { Lim et al., } \\
\quad 2001\end{array}$ & Singapore & $\begin{array}{l}\text { Cross- } \\
\text { sectional } \\
\text { study }\end{array}$ & $\begin{array}{l}\text { Workers from a } \\
\text { factory } \\
\text { producing } \\
\text { polyvinyl } \\
\text { chloride (PVC) } \\
\text { stabilizers } \\
\text { using lead } \\
\text { ingots as raw } \\
\text { materials (55) }\end{array}$ & $\begin{array}{c}35.73 \pm \\
9.59 \\
55 / 55 \\
(100 \%)\end{array}$ & $\begin{array}{c}24.1 \pm 9.6 \\
<20 \\
\mu \mathrm{g} / \mathrm{dL} \\
(18), 20-30 \\
\mu \mathrm{g} / \mathrm{dL} \\
(23),>30 \\
\mu \mathrm{g} / \mathrm{dL} \\
(14)\end{array}$ & & & $\begin{array}{c}\text { CRCL: } \\
(120.9 \pm \\
14.9)\end{array}$ & $\begin{array}{c}2 \text { partici- } \\
\text { pants with } \\
\text { CRCL }<90\end{array}$ & & & & & & \\
\hline
\end{tabular}


Table 1. Cont.

\begin{tabular}{|c|c|c|c|c|c|c|c|c|c|c|c|c|c|c|c|c|}
\hline \multirow[b]{2}{*}{$\begin{array}{l}\text { No. } \\
\text { (Ref) }\end{array}$} & \multirow[b]{2}{*}{$\begin{array}{l}\text { Author, } \\
\text { Year }\end{array}$} & \multirow[b]{2}{*}{$\begin{array}{c}\text { Study } \\
\text { Area } \\
\text { (Years of } \\
\text { the } \\
\text { Survey), } \\
\text { Exposed } \\
\text { Level }\end{array}$} & \multirow[b]{2}{*}{$\begin{array}{c}\text { Study } \\
\text { Design }\end{array}$} & \multirow[b]{2}{*}{$\begin{array}{l}\text { Participants } \\
\text { (Exposure and } \\
\text { Control } \\
\text { Groups) }\end{array}$} & \multicolumn{6}{|c|}{ Lead Exposure Group } & \multicolumn{6}{|c|}{ Non-Exposed Group } \\
\hline & & & & & $\begin{array}{c}\text { Mean/ } \\
\text { Median } \\
\text { Age, Male } \\
(\%)\end{array}$ & $\begin{array}{c}\text { BLL } \\
\text { Levels } \\
\text { ( } \mu \mathrm{g} / \mathrm{dL}), \\
\text { Duration } \\
\text { of } \\
\text { Exposure } \\
\text { (Years) }\end{array}$ & $\begin{array}{c}\text { BUN } \\
(\mathrm{mg} / \mathrm{dL})\end{array}$ & $\begin{array}{c}\text { Creatinine } \\
\text { (mg/dL), } \\
\text { Creati- } \\
\text { nine } \\
\text { Clearance } \\
\left(\mathrm{mL} / \mathrm{min}^{2} /\right. \\
\left.1.72 \mathrm{~m}^{2}\right)\end{array}$ & $\begin{array}{l}\text { Uric Acid } \\
\text { (mg/dL) }\end{array}$ & $\begin{array}{l}\text { Renal } \\
\text { Insuffi- } \\
\text { ciency } \\
(\mathrm{n}, \%)\end{array}$ & $\begin{array}{c}\text { Age, Male } \\
(\%)\end{array}$ & $\begin{array}{c}\text { BLL } \\
\text { Levels } \\
\text { ( } \mu \mathrm{g} / \mathrm{dL}), \\
\text { Duration } \\
\text { of } \\
\begin{array}{c}\text { Exposure } \\
\text { (Years) }\end{array}\end{array}$ & $\underset{(\mathrm{mg} / \mathrm{dL})}{\mathrm{BUN}}$ & $\begin{array}{c}\text { Creatinine } \\
\text { (mg/dL), } \\
\text { Creati- } \\
\text { nine } \\
\text { Clearance } \\
(\mathrm{mL} / \mathrm{min} / \\
\left.1.72 \mathrm{~m}^{2}\right)\end{array}$ & $\begin{array}{l}\text { Uric Acid } \\
\text { (mg/dL) }\end{array}$ & $\begin{array}{l}\text { Renal } \\
\text { Insuffi- } \\
\text { ciency } \\
(\mathrm{n}, \%)\end{array}$ \\
\hline $\begin{array}{c}23 . \\
{[44]}\end{array}$ & $\begin{array}{c}\text { Mujaj } \\
\text { et al., } 2019\end{array}$ & $\begin{array}{l}\text { USA } \\
(2015- \\
2017)\end{array}$ & $\begin{array}{l}\text { Cross- } \\
\text { sectional } \\
\text { study }\end{array}$ & $\begin{array}{l}\text { Newly hired } \\
\text { workers at s at } \\
\text { battery } \\
\text { manufacturing } \\
\text { and lead } \\
\text { recycling } \\
\text { plants in the } \\
\text { USA (447) }\end{array}$ & $\begin{array}{c}\text { BLL }<3.0 \\
(147): 28.8 \\
\pm 9.5), \\
\text { BLL } \\
3.1-6.3 \\
(152): 30.4 \\
\pm 11.4), \\
\text { BLL } \geq 6.3 \\
(148): 27.3 \\
\pm 5.3 \\
\text { Male \%: } \\
\text { NS }\end{array}$ & $\begin{array}{c}5.6 \pm 3.62 \\
\text { BLL <3.0: } \\
1.66 \\
(1.3-2.5) \\
\text { or } 1.78 \pm \\
0.4 \\
3.1-6.3: \\
4.63 \\
(3.9-5.7) \\
\text { or } 4.72 \pm \\
0.56, \geq 6.3: \\
10.48 \\
(7.9-12.25) \\
\text { or } 10.3 \pm \\
1.27\end{array}$ & & $\begin{array}{c}\text { BLL }<3.0 \\
\mu \mathrm{g} / \mathrm{dL} \\
(0.97 \pm \\
0.12), \\
3.1-6.3 \\
\mu \mathrm{g} / \mathrm{dL} \\
(0.99 \pm \\
0.14), \geq 6.3 \\
\mu \mathrm{g} / \mathrm{dL} \\
(0.96 \pm \\
0.13) \\
\text { eGFR: BLL } \\
<3.0 \\
\mu \mathrm{g} / \mathrm{dL} \\
(105.4 \pm \\
14.5), \\
3.1-6.3 \\
\mu \mathrm{d} \\
(102.6 \pm \\
16.0), \geq \\
6.3 \mu \mathrm{g} / \mathrm{dL} \\
(107.7 \pm \\
14.8)\end{array}$ & & $\begin{array}{c}\text { BLL }<3.0 \\
\mu \mathrm{g} / \mathrm{dL} \\
(147), \\
3.1-6.3 \\
\mu \mathrm{g} / \mathrm{dL} \\
(152), \geq \\
6.3 \mu \mathrm{g} / \mathrm{dL} \\
(148)\end{array}$ & & & & & & \\
\hline $\begin{array}{c}24 . \\
{[45]}\end{array}$ & $\begin{array}{l}\text { Muntner } \\
\text { et al., } 2003\end{array}$ & $\begin{array}{c}\text { USA } \\
(1988- \\
1994)\end{array}$ & $\begin{array}{l}\text { Retrospective } \\
\text { study }\end{array}$ & $\begin{array}{l}\text { Normotension } \\
\text { by the National } \\
\text { Center for } \\
\text { Health } \\
\text { statistics } \\
(10,398)\end{array}$ & $\begin{array}{c}\geq 20,4991 / \\
10,398 \\
(48 \%)\end{array}$ & $\begin{array}{c}3.30 \pm \\
0.10\end{array}$ & & $\begin{array}{c}1.05 \pm \\
0.004 \\
\text { eGFR: } 115 \\
\quad \pm 0.7\end{array}$ & & $\begin{array}{c}0.7-1.6 \\
\mu \mathrm{g} / \mathrm{dL} \\
(114), \\
1.7-2.8 \\
(166), \\
2.9-4.6 \\
\mu \mathrm{g} / \mathrm{dL} \\
(229), \\
4.7-52.9 \\
\mu \mathrm{g} / \mathrm{dL} \\
(270) \\
\text { CKD }(114)\end{array}$ & & & & & & \\
\hline
\end{tabular}


Table 1. Cont.

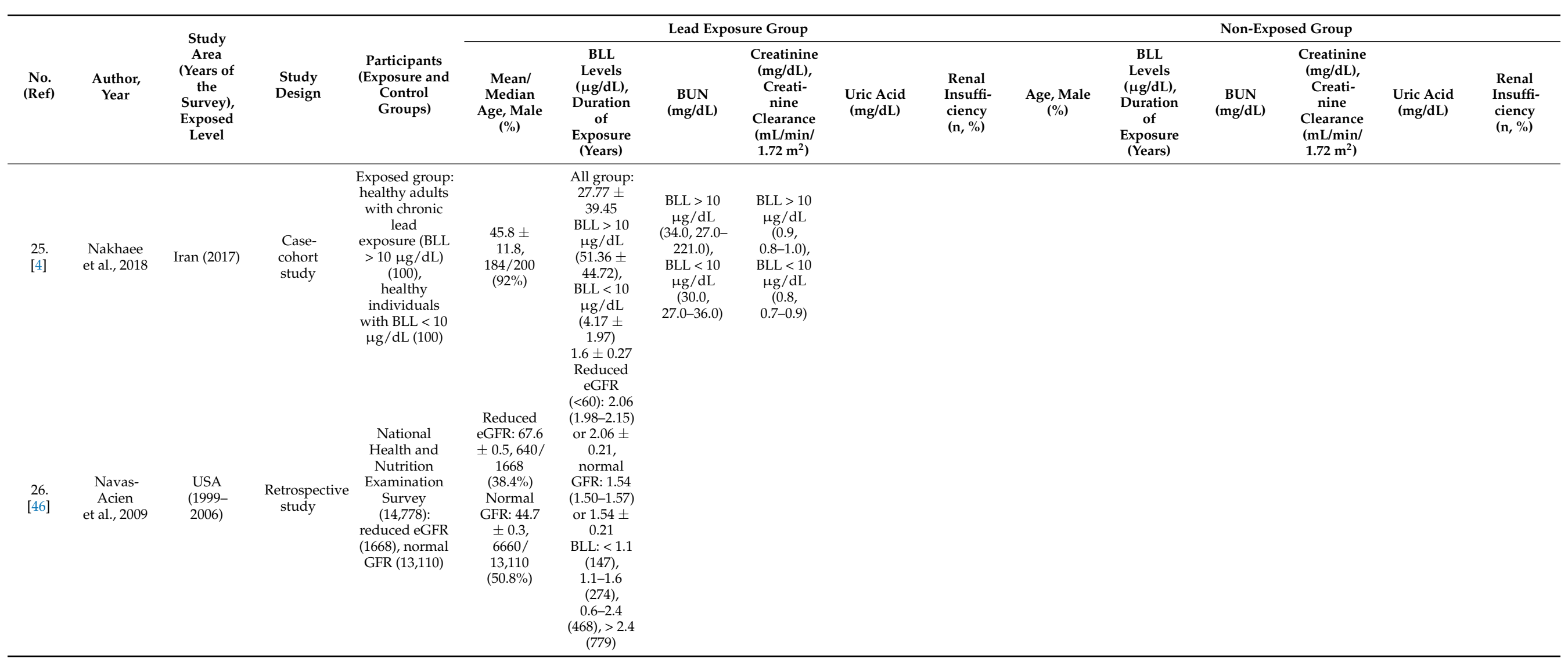


Table 1. Cont

\begin{tabular}{|c|c|c|c|c|c|c|c|c|c|c|c|c|c|c|c|c|}
\hline \multirow[b]{2}{*}{$\begin{array}{l}\text { No. } \\
\text { (Ref) }\end{array}$} & \multirow[b]{2}{*}{$\begin{array}{l}\text { Author, } \\
\text { Year }\end{array}$} & \multirow[b]{2}{*}{$\begin{array}{c}\text { Study } \\
\text { Area } \\
\text { (Years of } \\
\text { the } \\
\text { Survey), } \\
\text { Exposed } \\
\text { Level }\end{array}$} & \multirow[b]{2}{*}{$\begin{array}{c}\text { Study } \\
\text { Design }\end{array}$} & \multirow[b]{2}{*}{$\begin{array}{l}\text { Participants } \\
\text { (Exposure and } \\
\text { Control } \\
\text { Groups) }\end{array}$} & \multicolumn{6}{|c|}{ Lead Exposure Group } & \multicolumn{6}{|c|}{ Non-Exposed Group } \\
\hline & & & & & $\begin{array}{c}\text { Mean/ } \\
\text { Median } \\
\text { Age, Male } \\
\text { (\%) }\end{array}$ & $\begin{array}{c}\text { BLL } \\
\text { Levels } \\
\text { ( } \mu \mathrm{g} / \mathrm{dL}), \\
\text { Duration } \\
\text { of } \\
\text { Exposure } \\
\text { (Years) } \\
\end{array}$ & $\begin{array}{c}\text { BUN } \\
(\mathrm{mg} / \mathrm{dL})\end{array}$ & $\begin{array}{c}\text { Creatinine } \\
\text { (mg/dL), } \\
\text { Creati- } \\
\text { nine } \\
\text { Clearance } \\
\left(\mathrm{mL} / \mathrm{min}^{2} /\right. \\
\left.1.72 \mathrm{~m}^{2}\right) \\
\end{array}$ & $\begin{array}{l}\text { Uric Acid } \\
\text { (mg/dL) }\end{array}$ & $\begin{array}{l}\text { Renal } \\
\text { Insuffi- } \\
\text { ciency } \\
(\mathbf{n}, \%)\end{array}$ & $\underset{(\%)}{\text { Age, Male }}$ & $\begin{array}{c}\text { BLL } \\
\text { Levels } \\
\text { ( } \mu \mathrm{g} / \mathrm{dL}), \\
\text { Duration } \\
\text { of } \\
\text { Exposure } \\
\text { (Years) } \\
\end{array}$ & $\begin{array}{c}\text { BUN } \\
\text { (mg/dL) }\end{array}$ & $\begin{array}{c}\text { Creatinine } \\
\text { (mg/dL), } \\
\text { Creati- } \\
\text { nine } \\
\text { Clearance } \\
\left(\mathrm{mL} / \mathrm{min}^{2} /\right. \\
\left.1.72 \mathrm{~m}^{2}\right) \\
\end{array}$ & $\begin{array}{l}\text { Uric Acid } \\
\text { (mg/dL) }\end{array}$ & $\begin{array}{l}\text { Renal } \\
\text { Insuffi- } \\
\text { ciency } \\
(\mathbf{n}, \%)\end{array}$ \\
\hline $\begin{array}{l}27 . \\
{[47]}\end{array}$ & $\begin{array}{l}\text { Oktem } \\
\text { et al., 2004 }\end{array}$ & Turkey & $\begin{array}{l}\text { Cross- } \\
\text { sectional } \\
\text { study }\end{array}$ & $\begin{array}{l}\text { Auto repairers } \\
\text { (79), healthy } \\
\text { control (71) }\end{array}$ & $\begin{array}{c}17.3 \pm 1.0 \\
\text { NS }\end{array}$ & $\begin{array}{c}7.79 \pm 3.81 \\
\text { BLL; } \\
3.4-4.9 \\
\mu \mathrm{d} / \mathrm{dL} \\
(14): 4.11 \\
\pm 0.43 \\
5-9.9 \\
\mu \mathrm{g} / \mathrm{dL} \\
(51): 7.08 \\
\pm 1.38 \\
10-25 \\
\mu \mathrm{g} / \mathrm{dL} \\
(14): 14.04 \\
\pm 4.59\end{array}$ & $\begin{array}{c}12.8 \pm 2.3 \\
\text { BLL; } \\
3.4-4.9 \\
\mu \mathrm{g} / \mathrm{dL} \\
(14): 12.5 \\
\pm 2.5 \\
5-9.9 \\
\mu \mathrm{g} / \mathrm{dL} \\
(51): 12.9 \\
\pm 2.2 \\
10-25 \\
\mu \mathrm{d} / \mathrm{dL} \\
(14): 13.1 \\
\pm 2.6\end{array}$ & $\begin{array}{c}0.82 \pm \\
0.08 \\
\text { BLL; } \\
3.4-4.9 \\
\mu \mathrm{g} / \mathrm{dL} \\
(14): 0.83 \\
\pm 0.09 \\
5-9.9 \\
\mu \mathrm{g} / \mathrm{dL} \\
(51): 0.81 \\
\pm 0.08 \\
10-25 \\
\mu \mathrm{g} / \mathrm{dL} \\
(14): 0.84 \\
\pm 0.10 \\
\text { GFR: } 147 \\
\pm 16.1 \\
\text { BLL; } \\
3.4-4.9 \\
\mu \mathrm{g} / \mathrm{dL} \\
(14): 147 \pm \\
17.9,5-9.9 \\
\mu \mathrm{d}-\mathrm{dL} \\
(51): 149 \pm \\
15.6,10-25 \\
\mu \mathrm{g} / \mathrm{dL} \\
(14): 139 \pm \\
14.5\end{array}$ & $\begin{array}{c}5.6 \pm 1.1 \\
\text { BLL; } \\
3.4-4.9 \\
\mu \mathrm{g} / \mathrm{dL} \\
(14): 5.7 \pm \\
0.9,5-9.9 \\
\mu \mathrm{g} / \mathrm{dL} \\
(51): 5.5 \pm \\
1.1,10-25 \\
\mu \mathrm{g} / \mathrm{dL} \\
(14): 6.0 \pm \\
1.1 \\
\text { GFR: } 147 \\
\pm 16.1\end{array}$ & & $17.0 \pm 1.1$ & $\begin{array}{c}1.60 \pm \\
0.80\end{array}$ & $12.1 \pm 2.3$ & $\begin{array}{c}0.83 \pm \\
0.12 \\
\text { GFR: } 146 \\
\pm 18.5\end{array}$ & $5.9 \pm 1.4$ & \\
\hline
\end{tabular}


Table 1. Cont

\begin{tabular}{|c|c|c|c|c|c|c|c|c|c|c|c|c|c|c|c|c|}
\hline \multirow[b]{2}{*}{$\begin{array}{l}\text { No. } \\
\text { (Ref) }\end{array}$} & \multirow[b]{2}{*}{$\begin{array}{l}\text { Author, } \\
\text { Year }\end{array}$} & \multirow[b]{2}{*}{$\begin{array}{c}\text { Study } \\
\text { Area } \\
\text { (Years of } \\
\text { the } \\
\text { Survey), } \\
\text { Exposed } \\
\text { Level }\end{array}$} & \multirow[b]{2}{*}{$\begin{array}{l}\text { Study } \\
\text { Design }\end{array}$} & \multirow[b]{2}{*}{$\begin{array}{l}\text { Participants } \\
\text { (Exposure and } \\
\text { Control } \\
\text { Groups) }\end{array}$} & \multicolumn{6}{|c|}{ Lead Exposure Group } & \multicolumn{6}{|c|}{ Non-Exposed Group } \\
\hline & & & & & $\begin{array}{c}\text { Mean/ } \\
\text { Median } \\
\text { Age, Male } \\
(\%)\end{array}$ & $\begin{array}{c}\text { BLL } \\
\text { Levels } \\
\text { ( } \mu \mathrm{g} / \mathrm{dL}), \\
\text { Duration } \\
\text { of } \\
\text { Exposure } \\
\text { (Years) } \\
\end{array}$ & $\begin{array}{c}\text { BUN } \\
\text { (mg/dL) }\end{array}$ & $\begin{array}{c}\text { Creatinine } \\
\text { (mg/dL), } \\
\text { Creati- } \\
\text { nine } \\
\text { Clearance } \\
(\mathrm{mL} / \mathrm{min} / \\
\left.1.72 \mathrm{~m}^{2}\right) \\
\end{array}$ & $\begin{array}{l}\text { Uric Acid } \\
\text { (mg/dL) }\end{array}$ & $\begin{array}{l}\text { Renal } \\
\text { Insuffi- } \\
\text { ciency } \\
(\mathbf{n}, \%)\end{array}$ & $\begin{array}{c}\text { Age, Male } \\
(\%)\end{array}$ & $\begin{array}{c}\text { BLL } \\
\text { Levels } \\
\text { ( } \mu \mathrm{g} / \mathrm{dL}), \\
\text { Duration } \\
\text { of } \\
\text { Exposure } \\
\text { (Years) } \\
\end{array}$ & $\underset{(\mathrm{mg} / \mathrm{dL})}{\mathrm{BUN}}$ & $\begin{array}{c}\text { Creatinine } \\
\text { (mg/dL), } \\
\text { Creati- } \\
\text { nine } \\
\text { Clearance } \\
(\mathrm{mL} / \mathrm{min} / \\
\left.1.72 \mathrm{~m}^{2}\right) \\
\end{array}$ & $\begin{array}{l}\text { Uric Acid } \\
\text { (mg/dL) }\end{array}$ & $\begin{array}{l}\text { Renal } \\
\text { Insuffi- } \\
\text { ciency } \\
(\mathbf{n}, \%)\end{array}$ \\
\hline $\begin{array}{c}28 . \\
{[48]}\end{array}$ & $\begin{array}{l}\text { Omae } \\
\text { et al., } 1990\end{array}$ & $\begin{array}{l}\text { Japan } \\
(1985)\end{array}$ & $\begin{array}{l}\text { Cross- } \\
\text { sectional } \\
\text { study }\end{array}$ & $\begin{array}{c}\text { Lead exposed } \\
\text { workers (165): } \\
\text { duration of } \\
\text { exposed }>10 \\
\text { years (20), } \\
\text { duration of } \\
\text { exposed }<10 \\
\text { (134) }\end{array}$ & $\begin{array}{c}\text { 18.4-57.3 } \\
\text { NS }\end{array}$ & $\begin{array}{c}36.5(6-73) \\
\text { or 36.5 } \\
19.3 \\
0-19(21), \\
20-29(39), \\
30-39(34), \\
40-49(36), \\
50-59(25), \\
\geq 60(10) \\
\text { Duration } \\
\text { of } \\
\text { exposed: } \\
>10 \text { years: } \\
43.7 \\
\text { (23-73), } \\
\text { Duration } \\
\text { of exposed } \\
<10: 36.2 \\
(6-73)\end{array}$ & & $\begin{array}{c}0-19(1 \pm \\
1.13), \\
20-29 \\
(0.96 \pm \\
1.11), \\
30-39 \\
(0.96 \pm \\
1.14), \\
40-49 \\
(0.95 \pm \\
1.13,)^{\prime} \\
50-59 \\
(0.93 \pm \\
1.10), \geq 60 \\
(0.97 \pm \\
1.12) \\
\text { CRCL: } \\
0-19(99.3 \\
\pm 1.12), \\
20-29 \\
(105.4 \pm \\
1.13), \\
30-39 \\
(104.5 \pm \\
1.11, \\
40-49 \\
(105.3 \pm \\
1.14), \\
50-59 \\
(110.1 \pm \\
1.12), \geq 60 \\
(102.2 \pm \\
1.18)\end{array}$ & & & & & & & & \\
\hline
\end{tabular}


Table 1. Cont

\begin{tabular}{|c|c|c|c|c|c|c|c|c|c|c|c|c|c|c|c|c|}
\hline \multirow[b]{2}{*}{$\begin{array}{l}\text { No. } \\
\text { (Ref) }\end{array}$} & \multirow[b]{2}{*}{$\begin{array}{l}\text { Author, } \\
\text { Year }\end{array}$} & \multirow[b]{2}{*}{$\begin{array}{l}\text { Study } \\
\text { Area } \\
\text { (Years of } \\
\text { the } \\
\text { Survey), } \\
\text { Exposed } \\
\text { Level }\end{array}$} & \multirow[b]{2}{*}{$\begin{array}{c}\text { Study } \\
\text { Design }\end{array}$} & \multirow[b]{2}{*}{$\begin{array}{l}\text { Participants } \\
\text { (Exposure and } \\
\text { Control } \\
\text { Groups) }\end{array}$} & \multicolumn{6}{|c|}{ Lead Exposure Group } & \multicolumn{6}{|c|}{ Non-Exposed Group } \\
\hline & & & & & $\begin{array}{c}\text { Mean/ } \\
\text { Median } \\
\text { Age, Male } \\
\mathbf{( \% )}\end{array}$ & $\begin{array}{c}\text { BLL } \\
\text { Levels } \\
\text { ( } \mu \text { g/dL), } \\
\text { Duration } \\
\text { of } \\
\text { Exposure } \\
\text { (Years) }\end{array}$ & $\begin{array}{c}\text { BUN } \\
(\mathrm{mg} / \mathrm{dL})\end{array}$ & $\begin{array}{c}\text { Creatinine } \\
\text { (mg/dL), } \\
\text { Creati- } \\
\text { nine } \\
\text { Clearance } \\
\left(\mathrm{mL} / \mathrm{min}^{2} /\right. \\
\left.1.72 \mathrm{~m}^{2}\right)\end{array}$ & $\begin{array}{l}\text { Uric Acid } \\
\text { (mg/dL) }\end{array}$ & $\begin{array}{l}\text { Renal } \\
\text { Insuffi- } \\
\text { ciency } \\
(\mathbf{n}, \%)\end{array}$ & $\begin{array}{c}\text { Age, Male } \\
(\%)\end{array}$ & $\begin{array}{c}\text { BLL } \\
\text { Levels } \\
\text { ( } \mu \mathrm{g} / \mathrm{dL}), \\
\text { Duration } \\
\text { of } \\
\text { Exposure } \\
\text { (Years) }\end{array}$ & $\underset{(\mathrm{mg} / \mathrm{dL})}{\mathrm{BUN}}$ & $\begin{array}{c}\text { Creatinine } \\
\text { (mg/dL), } \\
\text { Creati- } \\
\text { nine } \\
\text { Clearance } \\
(\mathrm{mL} / \mathrm{min} / \\
\left.1.72 \mathrm{~m}^{2}\right)\end{array}$ & $\begin{array}{l}\text { Uric Acid } \\
(\mathrm{mg} / \mathrm{dL})\end{array}$ & $\begin{array}{l}\text { Renal } \\
\text { Insuffi- } \\
\text { ciency } \\
(\mathbf{n}, \%)\end{array}$ \\
\hline $\begin{array}{l}29 . \\
{[17]}\end{array}$ & $\begin{array}{l}\text { Onuegbu } \\
\text { et al., } 2011\end{array}$ & Nigeria & $\begin{array}{l}\text { Cross- } \\
\text { sectional } \\
\text { study }\end{array}$ & $\begin{array}{c}\text { Exposed } \\
\text { workers (53): } \\
\text { automobile } \\
\text { mechanics (23), } \\
\text { battery } \\
\text { repair workers } \\
\text { (11), petrol } \\
\text { station } \\
\text { attendants (19) } \\
\text { Control (42) }\end{array}$ & $\begin{array}{c}30.8 \pm 7.8 \\
53 / 53 \\
(100 \%)\end{array}$ & $\begin{array}{c}69.7 \pm \\
13.2 \\
\text { automobile } \\
\text { mechanics } \\
(68.8 \pm \\
14.8) \\
\text { battery } \\
\text { repair } \\
\text { workers } \\
(75.5 \pm \\
10.0), \\
\text { petrol } \\
\text { station } \\
\text { attendants } \\
(67.4 \pm \\
12.4)\end{array}$ & $\begin{array}{c}65 \pm 14.8 \\
\text { automobile } \\
\text { mechanics } \\
(69 \pm \\
14.7), \\
\text { battery } \\
\text { repair } \\
\text { workers } \\
(55.4 \pm \\
13.6), \\
\text { petrol } \\
\text { station } \\
\text { attendants } \\
(65.6 \pm \\
13.6)\end{array}$ & $\begin{array}{c}1.1 \pm 0.32 \\
\text { automobile } \\
\text { mechanics } \\
(1.09 \pm \\
0.04), \\
\text { battery } \\
\text { repair } \\
\text { workers }(1 \\
\pm 0.17), \\
\text { petrol } \\
\text { station } \\
\text { attendants } \\
(1.18 \pm \\
0.32)\end{array}$ & & & $\begin{array}{c}30.1 \pm 1.2 \\
42 / 42\end{array}$ & $18.5 \pm 3.6$ & $\begin{array}{c}53.2 \pm \\
13.6\end{array}$ & $\begin{array}{c}1.01 \pm \\
0.15\end{array}$ & & \\
\hline $\begin{array}{l}30 . \\
{[49]}\end{array}$ & $\begin{array}{l}\text { Patil et al., } \\
2007\end{array}$ & India & $\begin{array}{l}\text { Cross- } \\
\text { sectional } \\
\text { study }\end{array}$ & $\begin{array}{c}\text { All exposed } \\
\text { group (90) } \\
\text { Battery } \\
\text { manufacturing } \\
\text { industries (30), } \\
\text { silver jewelry } \\
\text { (30) } \\
\text { workers, spray } \\
\text { painters (30) } \\
\text { control group } \\
(35)\end{array}$ & $\begin{array}{l}20-40 \\
\text { years, } \\
90 / 90 \\
(100 \%)\end{array}$ & $\begin{array}{c}41.5 \pm 18.1 \\
\text { Battery } \\
\text { manufac- } \\
\text { turing } \\
\text { industries } \\
(53.6 \pm 17 \\
\text { silver } \\
\text { jewelry } \\
(48.6 \pm \\
7.39) \\
\text { workers, } \\
\text { spray } \\
\text { painters } \\
(22.3 \pm \\
8.87)\end{array}$ & $\begin{array}{c}25.7 \pm \\
9.59 \\
\text { Battery } \\
\text { manufac- } \\
\text { turing } \\
\text { industries } \\
(30.4 \pm \\
11), \text { silver } \\
\text { jewelry } \\
(20 \pm 5.84) \\
\text { workers, } \\
\text { spray } \\
\text { painters } \\
(26.7 \pm \\
8.34)\end{array}$ & $\begin{array}{c}0.85 \pm \\
0.19 \\
\text { Battery } \\
\text { manufac- } \\
\text { turing } \\
\text { industries } \\
(0.83 \pm \\
0.15), \\
\text { silver } \\
\text { jewelry } \\
(0.83 \pm 0.20) \\
\text { workers, } \\
\text { spray } \\
\text { painters } \\
(0.88 \pm 0.22)\end{array}$ & $\begin{array}{c}4.96 \pm \\
1.26 \\
\text { Battery } \\
\text { manufac- } \\
\text { turing } \\
\text { industries } \\
(5.92 \pm \\
0.95), \\
\text { silver } \\
\text { jewelry } \\
(4.07 \pm \\
1.01) \\
\text { workers, } \\
\text { spray } \\
\text { painters } \\
(4.90 \pm 1.10)\end{array}$ & & $\begin{array}{l}20-40 \\
\text { years, } \\
35 / 35\end{array}$ & $\begin{array}{l}12.52 \\
\pm 4.08\end{array}$ & $\begin{array}{l}25.12 \\
\pm 5.73\end{array}$ & $\begin{array}{c}0.81 \pm \\
0.11\end{array}$ & $\begin{array}{c}5.57 \pm \\
0.97\end{array}$ & \\
\hline $\begin{array}{l}31 . \\
{[50]}\end{array}$ & $\begin{array}{l}\text { Payton } \\
\text { et al., } 1994\end{array}$ & $\begin{array}{l}\text { USA } \\
(1988- \\
1991)\end{array}$ & $\begin{array}{l}\text { Cross- } \\
\text { sectional } \\
\text { study }\end{array}$ & $\begin{array}{c}\text { Men } \\
\text { participating in } \\
\text { the Normative } \\
\text { Aging Study } \\
\text { (744) }\end{array}$ & $\begin{array}{c}64 \pm 7.4 \\
\text { NS }\end{array}$ & $8.9 \pm 3.9$ & & $\begin{array}{c}1.3 \pm 0.2 \\
\text { CRCL: } \\
88.2 \pm 22 \\
\text { eGFR: } 71 \\
\pm 18.4\end{array}$ & & & & & & & & \\
\hline $\begin{array}{l}32 . \\
{[51]}\end{array}$ & $\begin{array}{c}\text { Reilly } \\
\text { et al., } 2018\end{array}$ & USA & $\begin{array}{l}\text { Cross- } \\
\text { sectional } \\
\text { study }\end{array}$ & $\begin{array}{l}\text { Smelter- } \\
\text { working } \\
\text { resident (52) } \\
\text { control } \\
\text { residents (290) }\end{array}$ & $\begin{array}{c}55.8 \pm \\
10.5, \text { NS }\end{array}$ & $\begin{array}{l}4.5 \pm 5 \\
\text { Duration } \\
\text { of } \\
\text { residence } \\
(14.1 \pm \\
12.2)\end{array}$ & & $\begin{array}{c}1.3 \pm 0.67 \\
\text { eGFR: } 85.2 \\
\quad \pm 26.5\end{array}$ & & & $43 \pm 14.1$ & $\begin{array}{c}2.7 \pm 2.5 \\
\text { Duration } \\
\text { of } \\
\text { residence } \\
(11.5 \pm \\
11.9)\end{array}$ & & $\begin{array}{c}1.2 \pm 0.66 \\
\text { eGFR: } 96 \\
\pm 24.2\end{array}$ & & \\
\hline
\end{tabular}


Table 1. Cont.

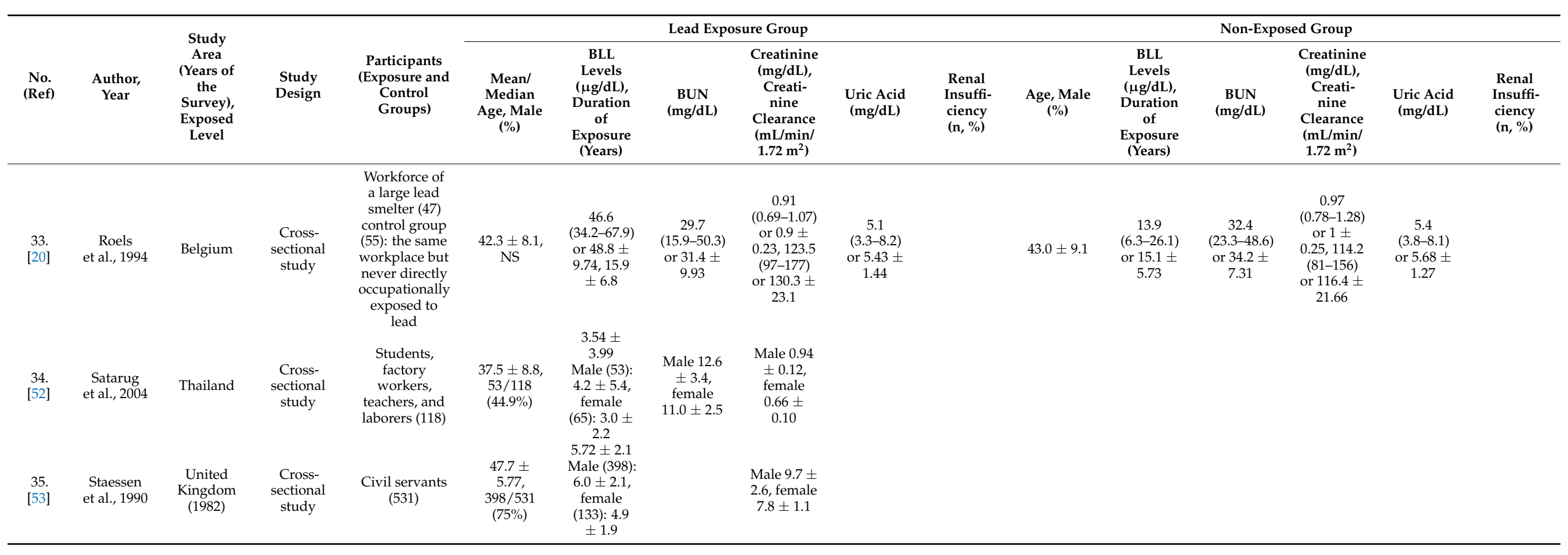


Table 1. Cont.

\begin{tabular}{|c|c|c|c|c|c|c|c|c|c|c|c|c|c|c|c|c|}
\hline \multirow[b]{2}{*}{$\begin{array}{l}\text { No. } \\
\text { (Ref) }\end{array}$} & \multirow[b]{2}{*}{$\begin{array}{l}\text { Author, } \\
\text { Year }\end{array}$} & \multirow[b]{2}{*}{$\begin{array}{l}\text { Study } \\
\text { Area } \\
\text { (Years of } \\
\text { the } \\
\text { Survey), } \\
\text { Exposed } \\
\text { Level }\end{array}$} & \multirow[b]{2}{*}{$\begin{array}{c}\text { Study } \\
\text { Design }\end{array}$} & \multirow[b]{2}{*}{$\begin{array}{l}\text { Participants } \\
\text { (Exposure and } \\
\text { Control } \\
\text { Groups) }\end{array}$} & \multicolumn{6}{|c|}{ Lead Exposure Group } & \multicolumn{6}{|c|}{ Non-Exposed Group } \\
\hline & & & & & $\begin{array}{c}\text { Mean/ } \\
\text { Median } \\
\text { Age, Male } \\
\text { (\%) }\end{array}$ & $\begin{array}{c}\text { BLL } \\
\text { Levels } \\
\text { ( } \mu \mathrm{g} / \mathrm{dL}), \\
\text { Duration } \\
\text { of } \\
\text { Exposure } \\
\text { (Years) }\end{array}$ & $\begin{array}{c}\text { BUN } \\
(\mathrm{mg} / \mathrm{dL})\end{array}$ & 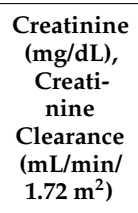 & $\begin{array}{l}\text { Uric Acid } \\
\text { (mg/dL) }\end{array}$ & $\begin{array}{l}\text { Renal } \\
\text { Insuffi- } \\
\text { ciency } \\
(\mathbf{n}, \%)\end{array}$ & $\begin{array}{c}\text { Age, Male } \\
(\%)\end{array}$ & $\begin{array}{c}\text { BLL } \\
\text { Levels } \\
\text { ( } \mu \mathrm{g} / \mathrm{dL}), \\
\text { Duration } \\
\text { of } \\
\begin{array}{c}\text { Exposure } \\
\text { (Years) }\end{array}\end{array}$ & $\begin{array}{c}\text { BUN } \\
(\mathrm{mg} / \mathrm{dL})\end{array}$ & $\begin{array}{c}\text { Creatinine } \\
\text { (mg/dL), } \\
\text { Creati- } \\
\text { nine } \\
\text { Clearance } \\
(\mathrm{mL} / \mathrm{min} /\end{array}$ & $\begin{array}{l}\text { Uric Acid } \\
\text { (mg/dL) }\end{array}$ & $\begin{array}{l}\text { Renal } \\
\text { Insuffi- } \\
\text { ciency } \\
(\mathbf{n}, \%)\end{array}$ \\
\hline $\begin{array}{l}36 . \\
{[54]}\end{array}$ & $\begin{array}{l}\text { Staessen } \\
\text { et al., } 1992\end{array}$ & $\begin{array}{l}\text { Belgium } \\
(1985- \\
1989)\end{array}$ & $\begin{array}{l}\text { Prospective } \\
\text { population- } \\
\text { based } \\
\text { Study }\end{array}$ & $\begin{array}{l}\text { Exposed group } \\
\text { (2327): the } \\
\text { Malmo Diet } \\
\text { and Cancer } \\
\text { Study } \\
\text { (MDCS-CC), } \\
\text { prospective } \\
\text { population- } \\
\text { based } \\
\text { study (MDCS) }\end{array}$ & $\begin{array}{c}48 \pm 16 \\
965 / \\
2327 \\
(41.5 \%)\end{array}$ & $\begin{array}{c}21.4 \pm 18.1 \\
\text { Male } 11.4 \\
(2.3-72.5) \\
\text { or } 24.4 \pm \\
20.3 \\
\text { female } 7.5 \\
(1.7-60.3) \\
\text { or } \\
19.3 \pm 16.9\end{array}$ & & $\begin{array}{c}\text { Male 1.24 } \\
\text { (0.7-4.64, } \\
\text { female } \\
\quad 1.05 \\
(0.58-2.71) \\
\text { CRCL: } \\
\text { Male 93 } \pm \\
30, \text { female } \\
480 \pm 25\end{array}$ & & & & & & & & \\
\hline $\begin{array}{l}37 . \\
{[55]}\end{array}$ & $\begin{array}{l}\text { Tsaih et al., } \\
2004\end{array}$ & USA & $\begin{array}{l}\text { Cohort } \\
\text { study }\end{array}$ & $\begin{array}{l}\text { The Normative } \\
\text { Aging Study } \\
\text { (NAS) }\end{array}$ & $\begin{array}{c}\text { Baseline } \\
(448): 66 \pm \\
6.6, \mathrm{NS}\end{array}$ & $\begin{array}{c}\text { Baseline } \\
(427): 6.5 \\
\pm 4.2 \\
\text { follow-up } \\
4.5 \pm 2.5\end{array}$ & & $\begin{array}{c}\text { Baseline } \\
(448): 1.1 \\
\pm 0.4 \\
\text { follow-up } \\
1.25 \pm 0.2\end{array}$ & & & & & & & & \\
\hline $\begin{array}{l}38 . \\
{[56]}\end{array}$ & $\begin{array}{l}\text { Verschoor } \\
\text { et al., } 1987\end{array}$ & Netherlands & $\begin{array}{l}\text { Cross- } \\
\text { sectional } \\
\text { study }\end{array}$ & $\begin{array}{c}155 \text { lead } \\
\text { workers (155): } \\
\text { lead battery } \\
\text { plants } 1(36), \\
\text { lead battery } \\
\text { plants } 2(52), \\
\text { lead battery } \\
\text { plants } 3(9), \\
\text { plastic } \\
\text { stabilizer } \\
\text { production } \\
\text { plant (58) } \\
\text { control } \\
\text { workers (126): } \\
\text { nonlead plants, } \\
\text { insulation } \\
\text { materials (60), } \\
\text { production of } \\
\text { drainpipes (56), } \\
\text { plant } \\
\text { producing } \\
\text { concrete (10) }\end{array}$ & $30-51$, NS & 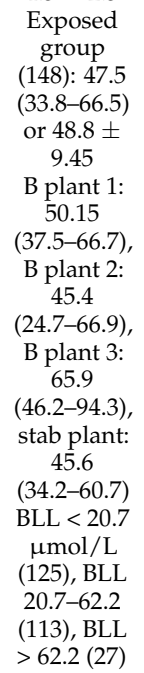 & $\begin{array}{c}56.6 \pm 14.1 \\
\text { BLL }<20.7 \\
(56.6 \pm \\
14.7), \text { BLL } \\
20.7-62.2 \\
(56.6 \pm \\
13.6), \text { BLL } \\
>62.2 \\
(56.6 \pm \\
13.6)\end{array}$ & $\begin{array}{c}0.96 \pm \\
0.16 \\
\text { BLL }<20.7 \\
(125): 0.96 \\
\pm 0.16 \\
\text { BLL } \\
20.7-62.2 \\
(113): 0.96 \\
\pm 0.15 \\
\text { BLL }>62.2 \\
(27): 0.92 \\
\pm 0.16 \\
\text { Relative } \\
\text { CRCL: } \\
0.17 \pm \\
0.09\end{array}$ & $\begin{array}{c}6.34 \pm 1.4 \\
\text { BLL }<20.7 \\
(6.29 \pm \\
1.34), \text { BLL } \\
20.7-62.2 \\
(6.42 \pm \\
1.38), \text { BLL } \\
>62.2 \\
(6.27 \pm \\
1.78) \\
\text { Relative } \\
\text { CRCL: } \\
0.17 \pm \\
0.09\end{array}$ & & $\begin{array}{l}30-51 \\
\text { years }\end{array}$ & $\begin{array}{c}0.40 \\
(0.27-0.58) \\
\text { or } 0.4 \pm \\
0.22\end{array}$ & & $\begin{array}{c}\text { Relative } \\
\text { CRCL: } \\
0.17 \pm \\
0.08\end{array}$ & & \\
\hline
\end{tabular}


Table 1. Cont

\begin{tabular}{|c|c|c|c|c|c|c|c|c|c|c|c|c|c|c|c|c|}
\hline \multirow[b]{2}{*}{$\begin{array}{c}\text { No. } \\
\text { (Ref) }\end{array}$} & \multirow[b]{2}{*}{$\begin{array}{l}\text { Author, } \\
\text { Year }\end{array}$} & \multirow[b]{2}{*}{$\begin{array}{c}\text { Study } \\
\text { Area } \\
\text { (Years of } \\
\text { the } \\
\text { Survey), } \\
\text { Exposed } \\
\text { Level }\end{array}$} & \multirow[b]{2}{*}{$\begin{array}{c}\text { Study } \\
\text { Design }\end{array}$} & \multirow[b]{2}{*}{$\begin{array}{l}\text { Participants } \\
\text { (Exposure and } \\
\text { Control } \\
\text { Groups) }\end{array}$} & \multicolumn{6}{|c|}{ Lead Exposure Group } & \multicolumn{6}{|c|}{ Non-Exposed Group } \\
\hline & & & & & $\begin{array}{c}\text { Mean/ } \\
\text { Median } \\
\text { Age, Male } \\
(\%)\end{array}$ & $\begin{array}{c}\text { BLL } \\
\text { Levels } \\
\text { ( } \mu \mathrm{g} / \mathrm{dL}), \\
\text { Duration } \\
\text { of } \\
\text { Exposure } \\
\text { (Years) }\end{array}$ & $\underset{(\mathrm{mg} / \mathrm{dL})}{\mathrm{BUN}}$ & 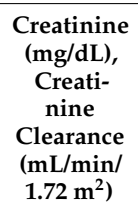 & $\begin{array}{l}\text { Uric Acid } \\
\text { (mg/dL) }\end{array}$ & $\begin{array}{l}\text { Renal } \\
\text { Insuffi- } \\
\text { ciency } \\
(\mathbf{n}, \%)\end{array}$ & $\begin{array}{c}\text { Age, Male } \\
\text { (\%) }\end{array}$ & $\begin{array}{c}\text { BLL } \\
\text { Levels } \\
\text { ( } \mu \mathrm{g} / \mathrm{dL}), \\
\text { Duration } \\
\text { of } \\
\begin{array}{c}\text { Exposure } \\
\text { (Years) }\end{array}\end{array}$ & $\underset{(\mathrm{mg} / \mathrm{dL})}{\text { BUN }}$ & $\begin{array}{c}\text { Creatinine } \\
\text { (mg/dL), } \\
\text { Creati- } \\
\text { nine } \\
\text { Clearance } \\
(\mathrm{mL} / \mathrm{min} / \\
\left.1.72 \mathrm{~m}^{2}\right)\end{array}$ & $\begin{array}{l}\text { Uric Acid } \\
(\mathrm{mg} / \mathrm{dL})\end{array}$ & $\begin{array}{l}\text { Renal } \\
\text { Insuffi- } \\
\text { ciency } \\
(\mathbf{n}, \%)\end{array}$ \\
\hline $\begin{array}{l}39 . \\
{[19]}\end{array}$ & $\begin{array}{l}\text { Wang } \\
\text { et al., } 2002\end{array}$ & Taiwan & $\begin{array}{l}\text { Cross- } \\
\text { sectional } \\
\text { study }\end{array}$ & $\begin{array}{c}\text { Lead battery } \\
\text { workers (229) }\end{array}$ & $\begin{array}{c}40 \pm 14.7 \\
120 / 229 \\
(52.4 \%)\end{array}$ & $\begin{array}{c}58.6 \pm \\
25.4 \\
\text { Male: } 67.7 \\
\pm 28.2, \\
\text { female: } \\
48.6 \pm \\
17.0 \\
\text { BLL <60 } \\
\mu \mathrm{g} / \mathrm{dL} \\
(134), \mathrm{BLL} \\
>60 \\
\mu \mathrm{g} / \mathrm{dL} \\
\text { (95) } \\
\text { Work } \\
\text { duration: } \\
8.24 \pm \\
8.25 \\
\text { Male: } 4.6 \\
(0.2-35) \text { or } \\
11.1 \pm \\
10.1, \\
\text { female: } 2.7 \\
(0.2-17) \text { or } \\
5.65 \pm \\
4.87\end{array}$ & $\begin{array}{c}\text { BLL }<60 \\
(14.37 \pm \\
0.35), \text { BLL } \\
>60(16.65 \\
\pm 0.43)\end{array}$ & $\begin{array}{c}\text { BLL }<60 \\
(1.04 \pm \\
0.01)), \text { BLL } \\
>60(1.05 \\
\pm 0.02) \\
\text { Abnormal } \\
\text { creatinine } \\
\text { BLL }<60 \\
(18), \text { BLL }> \\
60(23)\end{array}$ & $\begin{array}{c}\text { BLL }<60 \\
(5.66 \pm \\
0.12), \text { BLL } \\
>60(6.09 \\
\pm 0.15)\end{array}$ & 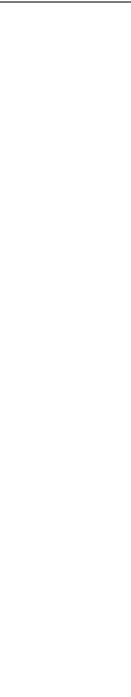 & & & & & & \\
\hline $\begin{array}{l}40 . \\
{[57]}\end{array}$ & $\begin{array}{c}\text { Wang } \\
\text { et al., } 2018\end{array}$ & $\begin{array}{l}\text { China } \\
\text { (2012) }\end{array}$ & $\begin{array}{l}\text { Cross- } \\
\text { sectional } \\
\text { study }\end{array}$ & $\begin{array}{l}\text { Lead exposure } \\
\text { paint workers }\end{array}$ & $\begin{array}{c}31.7 \pm \\
7.74 \\
706 / 747 \\
(94.5 \%)\end{array}$ & $\begin{array}{c}9.0 \pm 6.0 \\
(70) \\
\text { BLL } \\
\text { positive } \\
(70)\end{array}$ & & & & $\begin{array}{c}\text { Renal dys- } \\
\text { function } \\
\text { (93), BLL } \\
\text { positive } \\
\text { and renal } \\
\text { dysfunc- } \\
\text { tion } \\
(19 / 70), \\
\text { BLL } \\
\text { negative } \\
\text { and renal } \\
\text { dysfunc- } \\
\text { tion } \\
\text { (74/751) }\end{array}$ & & & & & & \\
\hline
\end{tabular}


Table 1. Cont.

\begin{tabular}{|c|c|c|c|c|c|c|c|c|c|c|c|c|c|c|c|c|}
\hline \multirow[b]{2}{*}{$\begin{array}{l}\text { No. } \\
\text { (Ref) }\end{array}$} & \multirow[b]{2}{*}{$\begin{array}{l}\text { Author, } \\
\text { Year }\end{array}$} & \multirow[b]{2}{*}{$\begin{array}{c}\text { Study } \\
\text { Area } \\
\text { (Years of } \\
\text { the } \\
\text { Survey), } \\
\text { Exposed } \\
\text { Level }\end{array}$} & \multirow[b]{2}{*}{$\begin{array}{c}\text { Study } \\
\text { Design }\end{array}$} & \multirow[b]{2}{*}{$\begin{array}{l}\text { Participants } \\
\text { (Exposure and } \\
\text { Control } \\
\text { Groups) }\end{array}$} & \multicolumn{6}{|c|}{ Lead Exposure Group } & \multicolumn{6}{|c|}{ Non-Exposed Group } \\
\hline & & & & & $\begin{array}{c}\text { Mean/ } \\
\text { Median } \\
\text { Age, Male } \\
(\%)\end{array}$ & $\begin{array}{c}\text { BLL } \\
\text { Levels } \\
\text { ( } \mu \mathrm{g} / \mathrm{dL}), \\
\text { Duration } \\
\text { of } \\
\text { Exposure } \\
\text { (Years) }\end{array}$ & $\begin{array}{c}\text { BUN } \\
(\mathrm{mg} / \mathrm{dL})\end{array}$ & $\begin{array}{c}\text { Creatinine } \\
\text { (mg/dL), } \\
\text { Creati- } \\
\text { nine } \\
\text { Clearance } \\
(\mathrm{mL} / \mathrm{min} / \\
\left.1.72 \mathrm{~m}^{2}\right)\end{array}$ & $\begin{array}{l}\text { Uric Acid } \\
\text { (mg/dL) }\end{array}$ & $\begin{array}{l}\text { Renal } \\
\text { Insuffi- } \\
\text { ciency } \\
(\mathbf{n}, \%)\end{array}$ & $\begin{array}{c}\text { Age, Male } \\
(\%)\end{array}$ & $\begin{array}{c}\text { BLL } \\
\text { Levels } \\
\text { ( } \mu \mathrm{g} / \mathrm{dL}), \\
\text { Duration } \\
\text { of } \\
\begin{array}{c}\text { Exposure } \\
\text { (Years) }\end{array}\end{array}$ & $\underset{(\mathrm{mg} / \mathrm{dL})}{\mathrm{BUN}}$ & $\begin{array}{c}\text { Creatinine } \\
\text { (mg/dL), } \\
\text { Creati- } \\
\text { nine } \\
\text { Clearance } \\
(\mathrm{mL} / \mathrm{min} / \\
\left.1.72 \mathrm{~m}^{2}\right)\end{array}$ & $\begin{array}{l}\text { Uric Acid } \\
\text { (mg/dL) }\end{array}$ & $\begin{array}{c}\text { Renal } \\
\text { Insuffi- } \\
\text { ciency } \\
(\mathrm{n}, \%)\end{array}$ \\
\hline $\begin{array}{c}41 . \\
{[58]}\end{array}$ & $\begin{array}{l}\text { Weaver } \\
\text { et al., } 2011\end{array}$ & $\begin{array}{c}\text { Republic } \\
\text { of Korea } \\
(2004- \\
2005)\end{array}$ & $\begin{array}{l}\text { Cohort } \\
\text { study }\end{array}$ & $\begin{array}{c}\text { Current and } \\
\text { former } \\
\text { workers } \\
\text { employed at } 26 \\
\text { lead-using } \\
\text { facilities (712) }\end{array}$ & $\begin{array}{c}47.6 \pm 7.9 \\
563 / 712 \\
(79 \%)\end{array}$ & $\begin{array}{c}23.1 \pm 14.1 \\
\text { Duration } \\
\text { of } \\
\text { exposed: } \\
13.1 \pm 7.3\end{array}$ & & $\begin{array}{c}0.87 \pm \\
0.15 \\
\text { eGFR: } 97.4 \\
\pm 19.2 \\
\text { CRCL: } \\
111.1 \pm \\
30.7\end{array}$ & & & & & & & & \\
\hline $\begin{array}{l}43 . \\
{[60]}\end{array}$ & $\begin{array}{l}\text { Weaver } \\
\text { et al., } 2005\end{array}$ & $\begin{array}{c}\text { Republic } \\
\text { of Korea } \\
(1997- \\
1999)\end{array}$ & $\begin{array}{l}\text { Cohort } \\
\text { study }\end{array}$ & $\begin{array}{c}\text { Current and } \\
\text { former lead } \\
\text { workers (803): } \\
\text { lead battery, } \\
\text { lead oxide, } \\
\text { lead crystal, } \\
\text { radiator } \\
\text { manufacture, } \\
\text { and secondary } \\
\text { lead smelting } \\
\text { controls (135) } \\
\text { Workers from } \\
26 \text { plants that } \\
\text { produced lead } \\
\text { batteries, lead } \\
\text { oxide, lead } \\
\text { crystal, or } \\
\text { radiators or } \\
\text { secondary lead } \\
\text { smelters (652) }\end{array}$ & $\begin{array}{c}40.4 \pm \\
10.1 \\
639 / 803 \\
(79.6 \%)\end{array}$ & $\begin{array}{c}32.0 \pm \\
15.0 \\
\text { Duration } \\
\text { of job: } 8.2 \\
\pm 6.5\end{array}$ & $14.4 \pm 3.7$ & $\begin{array}{c}0.90 \pm \\
0.16 \\
\text { CRCL: } \\
94.7 \pm \\
20.7\end{array}$ & $\begin{array}{c}109.2 \pm \\
34.8\end{array}$ & & $\begin{array}{c}34.5 \pm 9.1 \\
124 / 135\end{array}$ & $5.3 \pm 1.8$ & $13.1 \pm 2.9$ & $\begin{array}{c}0.91 \pm \\
0.10 \\
\text { CRCL: } \\
108.4 \pm \\
19.4\end{array}$ & & \\
\hline
\end{tabular}

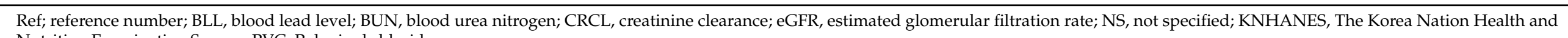
Nutrition Examination Survey; PVC, Polyvinyl chloride. 


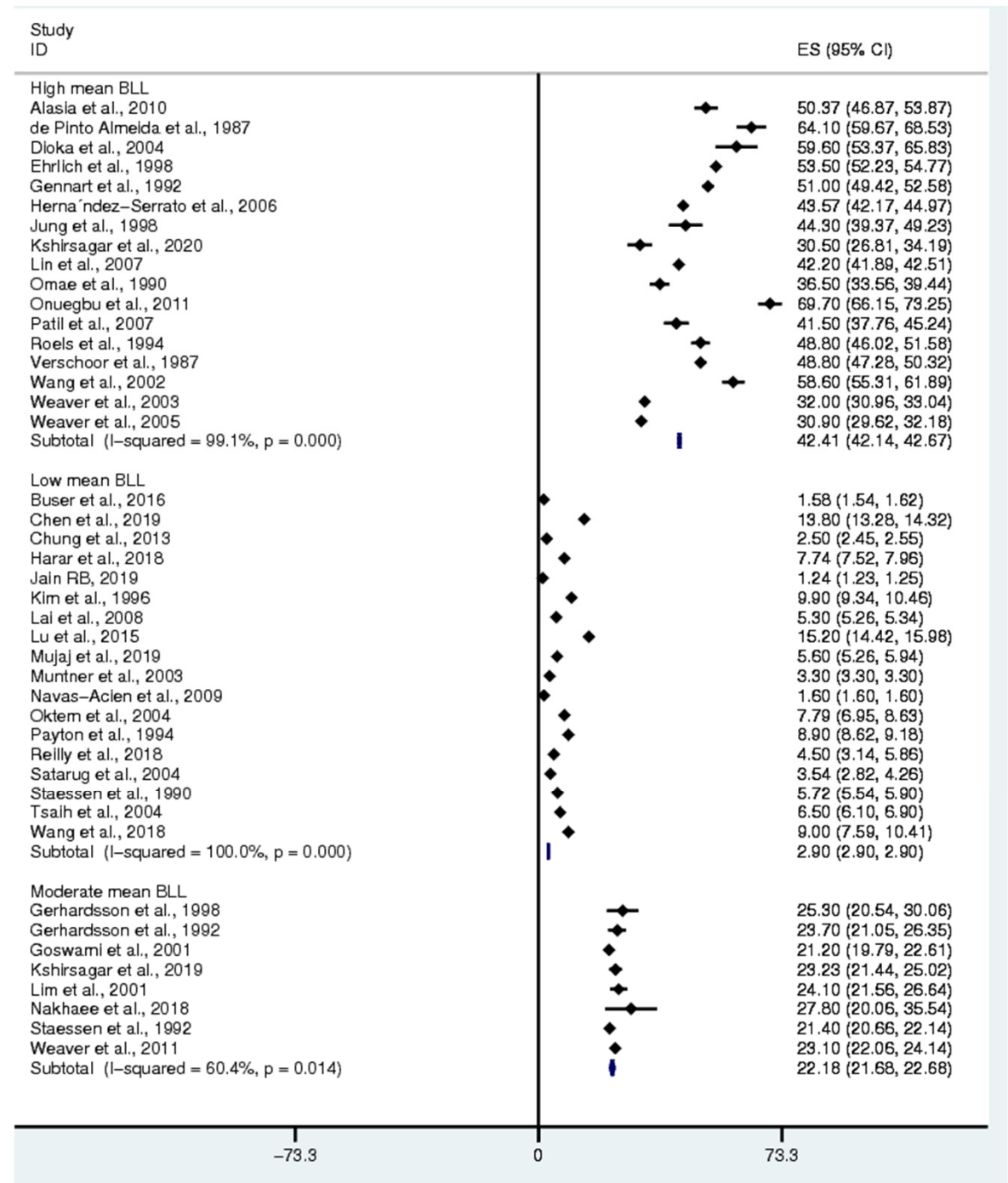

Figure 2. The mean BLL among participants. ES: Effect Size (mean BLL in ug/dL), CI: Confidence Interval (ug/dL), black diamond symbol: point estimate, solid line in the middle of the graph at 0 : zero effect size.

Table 2. Sources of lead contamination among exposed participants.

\begin{tabular}{ll}
\hline & $\begin{array}{l}\text { Sources of contamination: welding and metal, paint and pigment, } \\
\text { radiator repair, petrol, auto mechanic, battery makers and } \\
\text { chargers, glazed pottery, plastic stabilizer industry, radiator } \\
\text { manufacturing industry, storage battery plant, automobile } \\
\text { mechanic, petrol station, silver jewelry, lead battery plants, } \\
\text { production plant, lead oxide, and lead crystal }\end{array}$ \\
\hline $\begin{array}{l}\text { Moderate mean BLL } / \mathrm{dL}) \\
(20-30 \mu \mathrm{g} / \mathrm{dL})\end{array}$ & $\begin{array}{l}\text { Sources of contamination: smelting, batteries, pigment, extruded } \\
\text { materials, cable sheeting, gas add, silver jewelry, PVC-producing } \\
\text { factory, stabilizers using lead ingots, lead-using facilities }\end{array}$ \\
\hline $\begin{array}{l}\text { Low mean BLL } \\
(<20 \mu \mathrm{g} / \mathrm{dL})\end{array}$ & $\begin{array}{l}\text { Sources of contamination: polluted areas, heavy metal pollution, } \\
\text { battery manufacturing and lead recycling plants, auto repair, } \\
\text { smelting factory }\end{array}$ \\
\hline
\end{tabular}

\subsection{Pooled Mean Difference in BLL between Exposed and Control Participants}

The pooled mean difference in BLL between the exposed and non-exposed participants was estimated using the mean BLL from 17 studies [7,15-17,20,30,32-34,39,41,42,47,49,51, 56,59] (Figure 3). Overall, the mean BLL of the exposed group was higher than that of 
the non-exposed participants (weighted mean difference: $25.5, p<0.0001,95 \%$ CI: $18.59-$ $\left.32.45, \mathrm{I}^{2}: 99.8 \%\right)$. Subgroup analysis demonstrated that the difference in BLL between exposed and non-exposed participants was larger for those with high mean BLL (weighted mean difference: $32.28, p<0.0001,95 \%$ CI: 28.91-35.65, $\mathrm{I}^{2}: 96.4 \%$ ), whereas the difference between exposed and non-exposed participants was smallest for those with a low mean BLL (weighted mean difference: 4.73, $p<0.0001,95 \%$ CI: 2.69-6.76, $\mathrm{I}^{2}: 93.6 \%$ ).

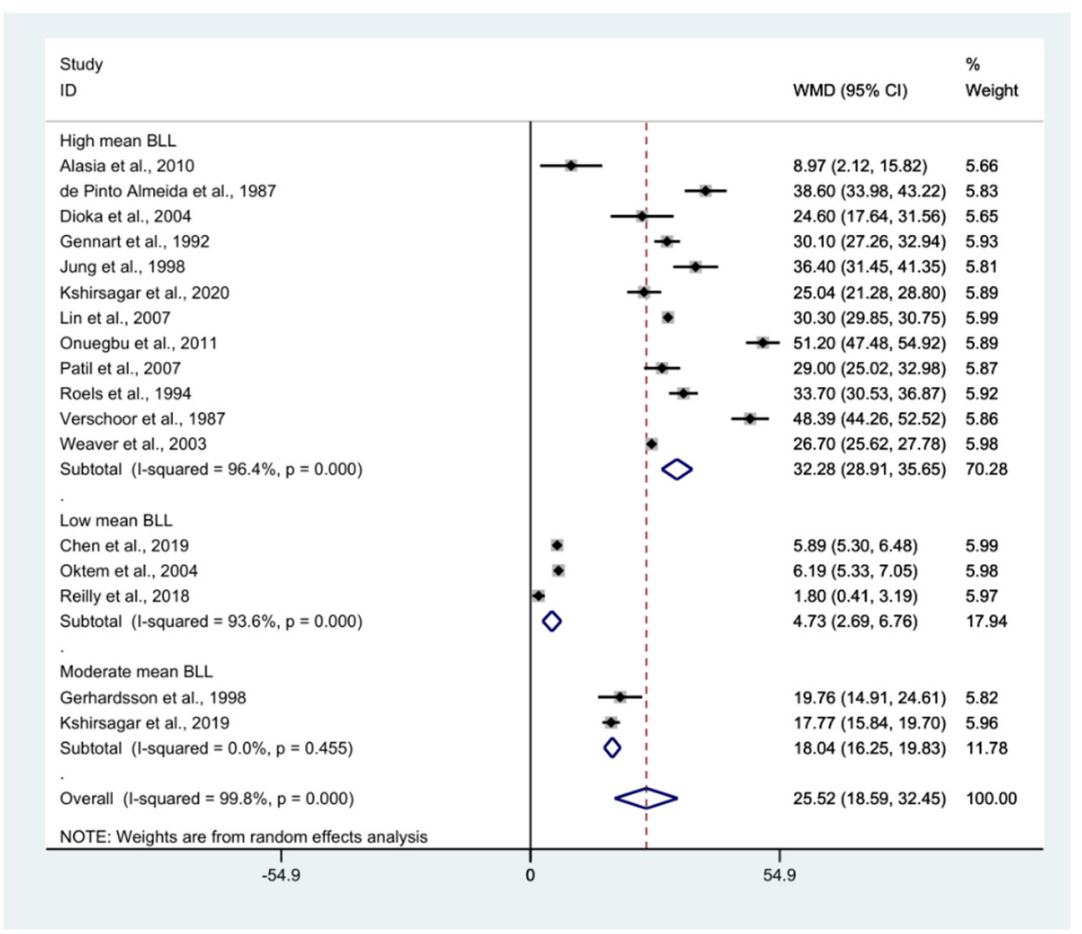

Figure 3. The mean difference in BLL between exposed and non-exposed participants. WMD: Weighted Mean Difference ( $\mu \mathrm{g} / \mathrm{dL}), \%$ Weighted: the impact proportion of each study to the pooled effect, CI: Confidence Interval $(\mu \mathrm{g} / \mathrm{dL})$, Black diamond symbol: point estimate for each study, White diamond symbol: pooled WMD in each subgroup or all groups, Solid line in the middle of the graph at 0: no difference in WMD between the two groups, Dashed line: pooled WMD between the two groups.

\subsection{BLL and Gender}

The pooled mean difference in BLL between the exposed men and women was estimated using five studies [11,19,52-54]. The results demonstrated that the mean BLL in the exposed males was higher than that in the female participants (weighted mean difference: $2.45, p<0.0001,95 \%$ CI: $1.11-3.80, \mathrm{I}^{2}: 95.8 \%$ ) (Figure 4). Three studies [19,53,54] demonstrated a higher mean BLL in male participants than in female participants.

\subsection{Renal Function Tests}

The difference in renal function parameters, including BUN, creatinine, uric acid, and creatinine clearance, of the exposed and non-exposed participants was estimated. The pooled mean difference in BUN between the two groups was estimated from 10 studies $[7,15,17,20,32,39,41,47,49,59]$. The results demonstrated that the mean BUN in the exposed group was higher than that in the non-exposed participants (weighted mean difference: 1.66, $p<0.0001,95 \%$ CI: 0.76-2.55, $\mathrm{I}^{2}: 76 \%$ ) (Figure 5). The pooled mean difference in creatinine between the two groups was estimated from 15 studies [7,15-17,20,30,32,33,35,39,41,47,49,51,59]. The results demonstrated that the mean creatinine in the exposed participants was higher than that in the non-exposed participants (weighted mean difference: $0.05, p: 0.007,95 \%$ CI: 0.01-0.08, $\mathrm{I}^{2}: 76.8 \%$ ) (Figure 6). The pooled mean difference in uric acid between the two groups was estimated from 9 studies $[7,15,16,20,32,39,41,47,49]$. The results demon- 
strated no difference in the mean uric acid of the exposed and non-exposed participants (weighted mean difference: 0.51, p: 0.061, 95\% CI: -0.024-1.06, I²: 91.6\%) (Supplementary Figure S1). The pooled mean difference in creatinine clearance between the two groups was estimated from 8 studies $[15,20,30,33,47,51,56,59]$. The results demonstrated that the mean creatinine clearance in the exposed participants was lower than that in the non-exposed participants (standard mean difference: $-0.544, p: 0.03,95 \%$ CI: $\left.-1.035-(-0.054), \mathrm{I}^{2}: 96.2 \%\right)$ (Supplementary Figure S2).

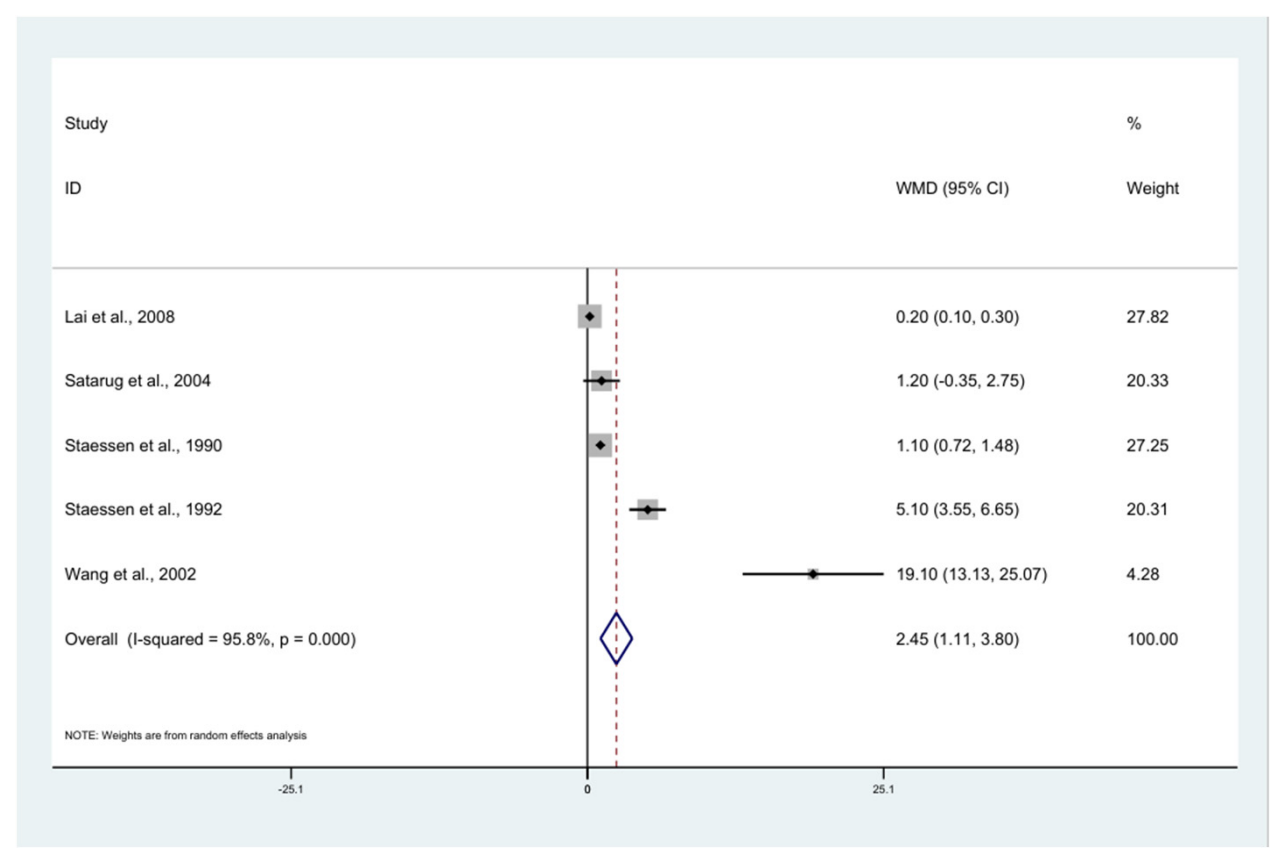

Figure 4. The mean difference in BLL between male and female participants. The mean BLL in the exposed males was higher than that in the female participants (weighted mean difference: 2.45, $p<0.0001,95 \%$ CI: 1.11-3.80, $\mathrm{I}^{2}:$ 95.8\%) (white diamond symbol). WMD: Weighted Mean Difference $(\mu \mathrm{g} / \mathrm{dL}), \%$ Weighted: the impact proportion of each study to the pooled effect, CI: Confidence Interval $(\mu \mathrm{g} / \mathrm{dL})$, Black diamond symbol: point estimate for each study, White diamond symbol: pooled WMD in each subgroup or all groups, Solid line in the middle of the graph at 0 : no difference in WMD between the two groups, Dashed line: pooled WMD between the two groups.

\subsection{Renal Function Tests and BLL}

Meta-regression analyses were performed to determine the association between the effect size (weighted mean difference, WMD) of renal function test parameters (dependent variable) and mean BLL (independent variable). The meta-regression of BUN (weighted mean difference) and mean BLL was performed using the data from 10 studies $[7,15,17,20,32,39,41,47,49,59]$ because these studies reported the mean BLL and mean BUN. The results demonstrated a significant positive effect of BLL on BUN (weighted mean difference) ( $p=0.022$, coefficient: 0.75 , constant: -3.7 ) (Figure 7). The meta-regression of creatinine (weighted mean difference) and mean BLL was performed using the data from 15 studies $[7,15-17,20,30,32,33,35,39,41,47,49,51,59]$. The results demonstrated a nonsignificant effect of mean BLL on creatinine level (weighted mean difference) $(p=0.989)$ (Figure 8). The meta-regression of mean BLL and the BUN/creatinine ratio (weighted mean difference) was performed using the data from 10 studies $[7,15,17,20,32,39,41,47,49,59]$. The results demonstrated a non-significant effect of mean BLL on the BUN/creatinine ratio (weighted mean difference) ( $p=0.889$, coefficient: 0.12, constant: 0.034) (Figure 9). No significant effect of mean BLL on creatinine clearance or uric acid was found (Supplementary Figures S3 and S4). 


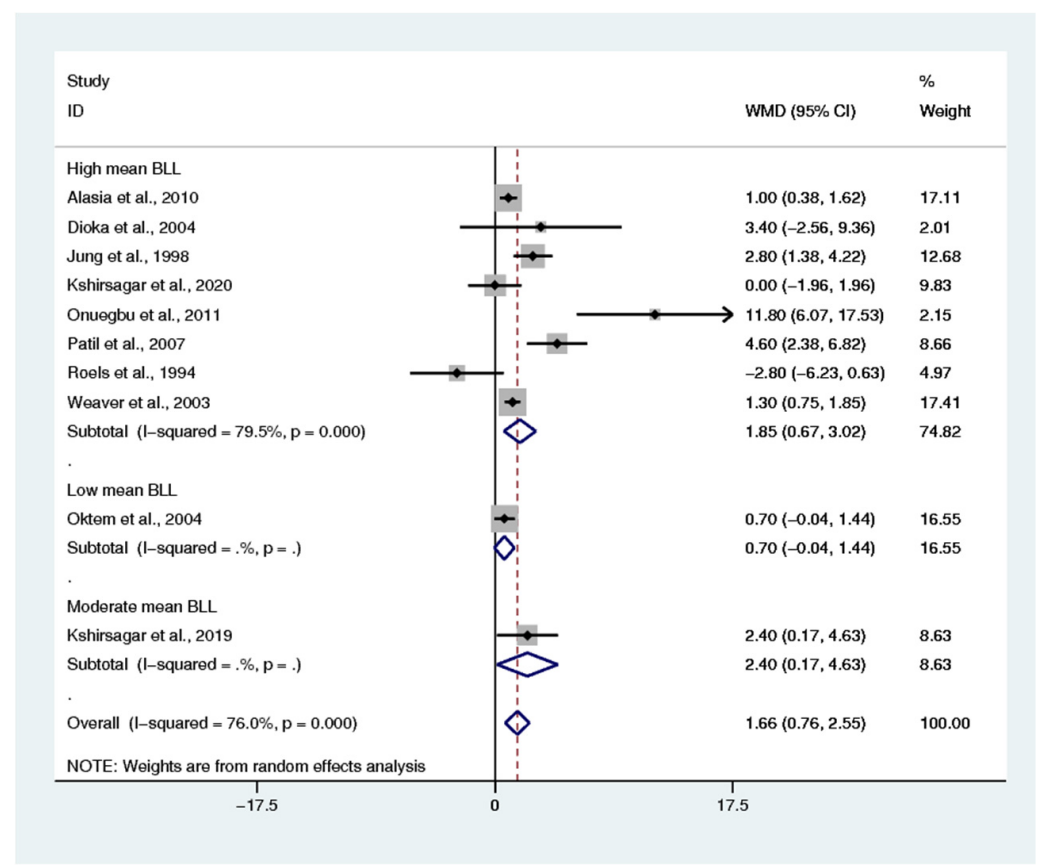

Figure 5. The mean difference in blood urea nitrogen (BUN) levels between exposed and non-exposed participants. WMD: Weighted Mean Difference (mg/dL), \% Weighted: the impact proportion of each study to the pooled effect, CI: Confidence Interval (mg/dL), Black diamond symbol: point estimate for each study, White diamond symbol: pooled WMD in each subgroup or all groups, Solid line in the middle of the graph at 0: no difference in WMD between the two groups, Dashed line: pooled WMD between the two groups.

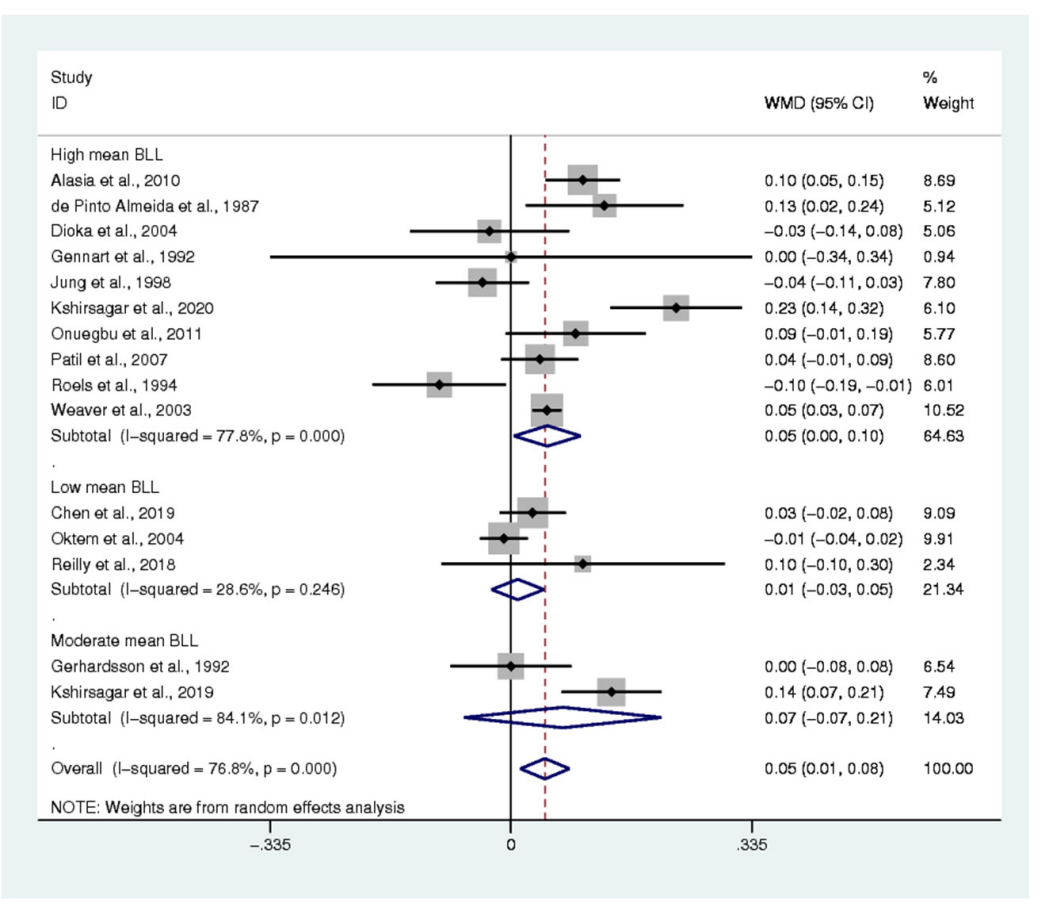

Figure 6. The mean difference in creatine levels between exposed and non-exposed participants. WMD: Weighted Mean Difference (mg/dL), \% Weighted: the impact proportion of each study to the pooled effect, CI: Confidence Interval (mg/dL), Black diamond symbol: point estimate for each study, White diamond symbol: pooled WMD in each subgroup or all groups, Solid line in the middle of the graph at 0: no difference in WMD between the two groups, Dashed line: pooled WMD between two groups. 


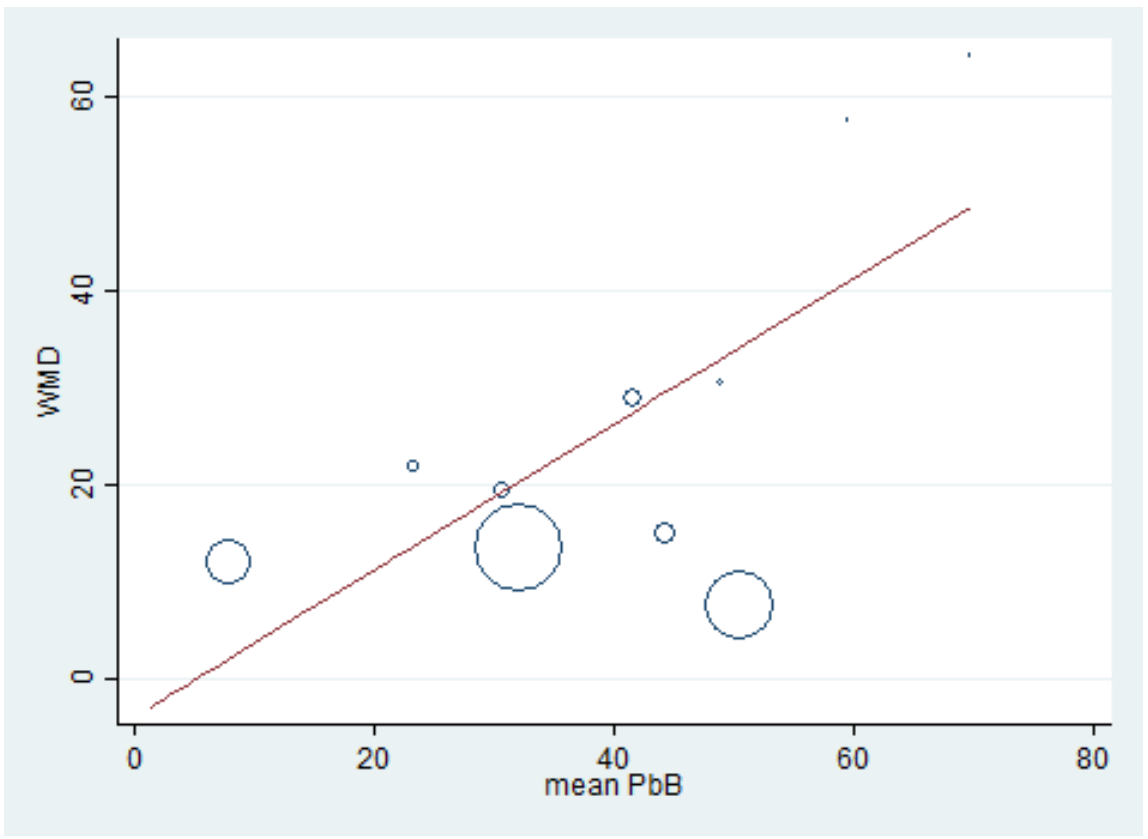

Figure 7. The meta-regression analysis of WMD (BUN) and mean BLL ( $\mu \mathrm{g} / \mathrm{dL})$. WMD: Weighted Mean Difference, BUN: Blood Urea Nitrogen (mg/dL), PbB: Blood Lead ( $\mu \mathrm{g} / \mathrm{dL})$.

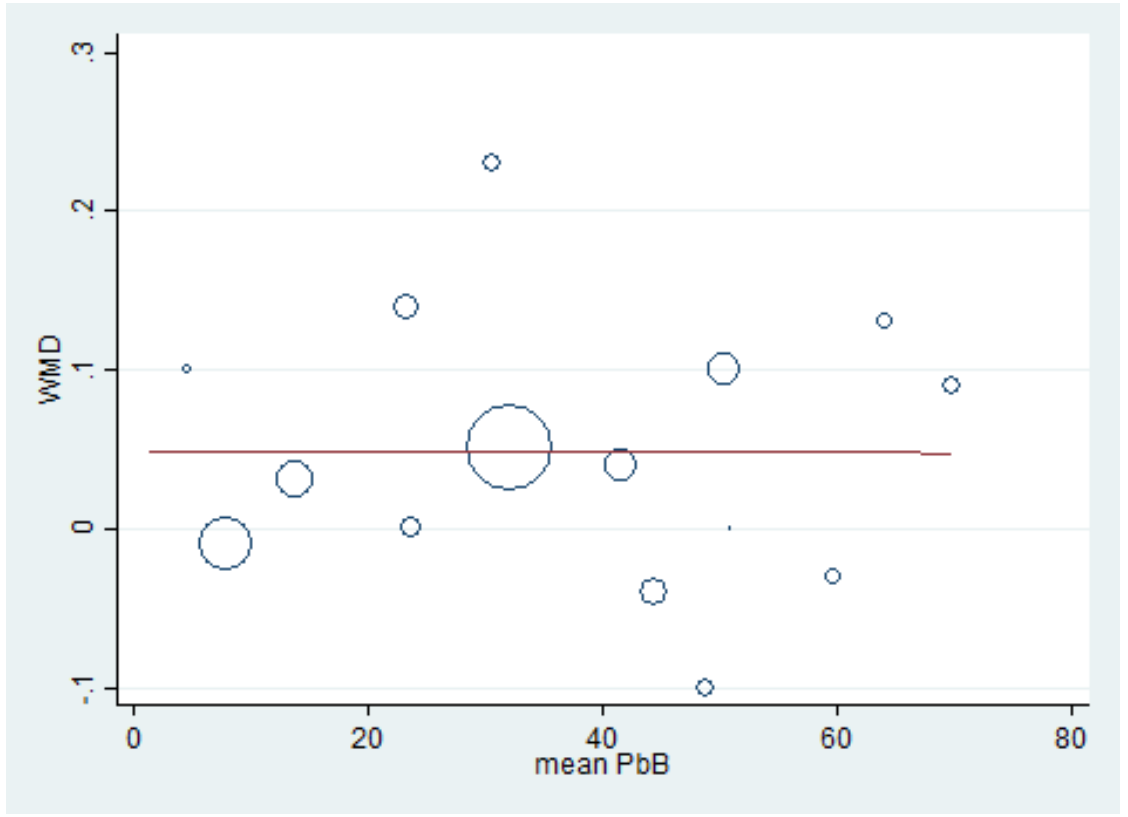

Figure 8. Meta-regression analysis of WMD (creatinine) and mean BLL ( $\mu \mathrm{g} / \mathrm{dL})$. WMD: Weighted Mean Difference, PbB: Blood Lead ( $\mu \mathrm{g} / \mathrm{dL})$.

\subsection{Publication Bias}

The funnel plot between the effect size (weighted mean difference) and standard error of the effect size demonstrated the likelihood of asymmetry (Figure 10). Therefore, Egger's test was performed to confirm the funnel plot asymmetry. The results showed that no small-study effects among the included studies were found $(p<0.728)$, indicating no publication bias across the included studies. 


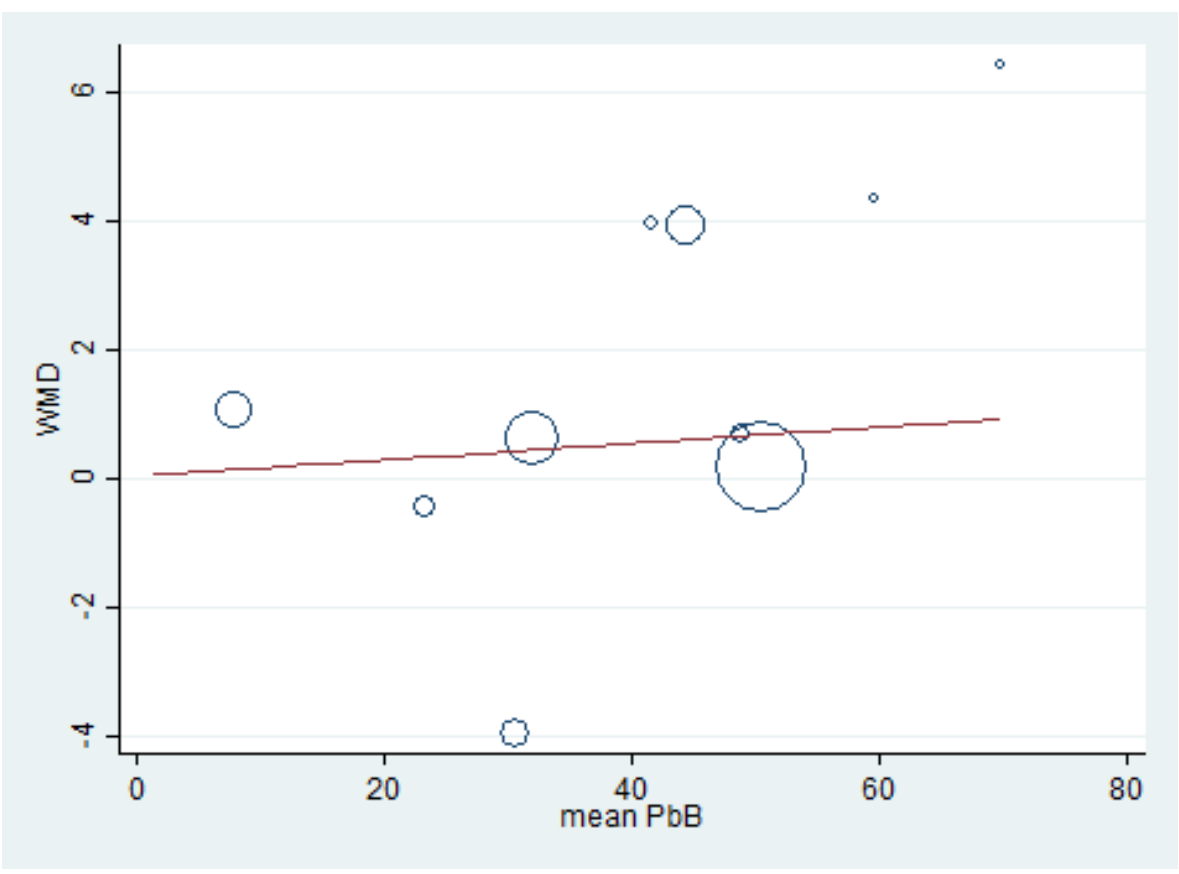

Figure 9. Meta-regression analysis of WMD and the BUN/creatinine ratio. WMD: Weighted Mean Difference, BUN: Blood Urea Nitrogen (mg/dL), PbB: Blood Lead ( $\mu \mathrm{g} / \mathrm{dL})$.

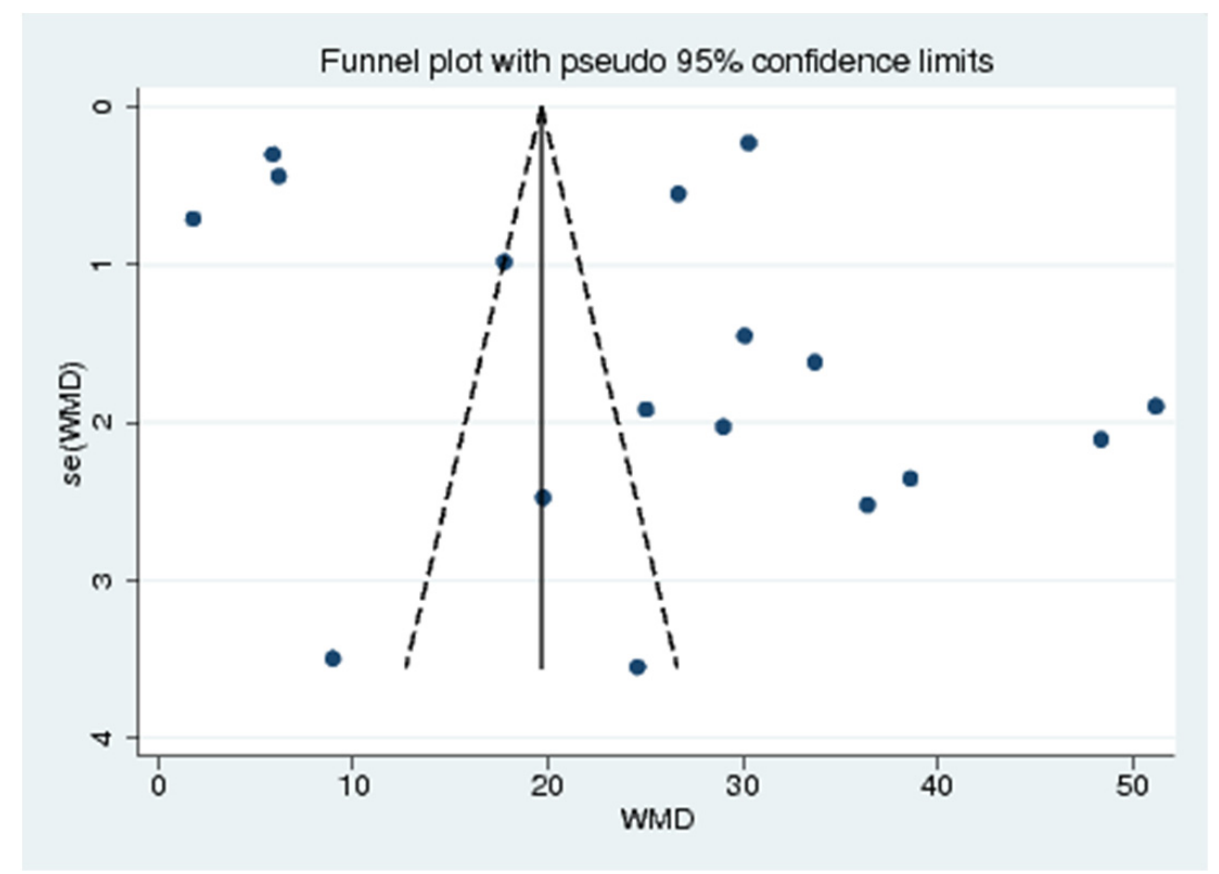

Figure 10. Funnel plot. WMD: Weighted Mean Difference, se (WMD): Standard Error (Weighted Mean Difference)

\section{Discussion}

The present meta-analysis demonstrated that the mean BLL among participants with high BLL was $42.41 \mu \mathrm{g} / \mathrm{dL}$, moderate BLL was $22.18 \mu \mathrm{g} / \mathrm{dL}$, and low BLL was $2.90 \mu \mathrm{g} / \mathrm{dL}$. The mean BLL was significantly higher in lead-exposed participants than in non-exposed participants for all 18 included studies. This finding was similar to a meta-analysis performed in Iran, which demonstrated high mean BLL in Iranian leadexposed workers [21]. Moreover, the high difference in BLL seemed to be observed clearly 
among participants with high BLL compared to those with moderate or low BLL. Various studies supported this difference in the mean BLL among the two groups of participants. In Brazil, de Pinto Almeida et al. demonstrated that the mean BLL was $64.1 \pm 16.3 \mu \mathrm{g} / \mathrm{dL}$ and $25.5 \pm 4.4 \mu \mathrm{g} / \mathrm{dL}$ in primary lead smelting workers and in non-exposed participants, respectively [16]. In Germany, it was reported that the mean BLL was 40.6 (20.2-70.6) $\mu \mathrm{g} / \mathrm{dL}$ in workers who were exposed to lead dust in an accumulator plant, whereas the mean BLL was 6.8 (4.8-10.6) $\mu \mathrm{g} / \mathrm{dL}$ in the control group [12]. In South Africa, Ehrlich et al. reported that the mean BLL in battery factory workers was $53.5 \pm 12.7 \mu \mathrm{g} / \mathrm{dL}$ [13]. In India, Patil et al. showed that the mean BLL in battery manufacturing workers, silver jewelry workers, spray painters, and controls was $53.63 \pm 16.98,48.56 \pm 7.39,22.32 \pm 8.87$, and $12.52 \pm 4.08 \mu \mathrm{g} / \mathrm{dL}$, respectively [49]. In Nigeria, Alasia et al. showed that the mean BLL was $50.37 \pm 24.58 \mu \mathrm{g} / \mathrm{dL}$ in lead-exposed workers and $41.40 \pm 26.85 \mu \mathrm{g} / \mathrm{dL}$ in non-exposed participants [61]. Onuegbu et al. performed a study on automobile mechanics, battery repair workers, and petrol station attendants and demonstrated that the mean BLL was $69.7 \pm 13.2 \mu \mathrm{g} / \mathrm{dL}$ in lead-exposed group and $18.5 \pm 3.6 \mu \mathrm{g} / \mathrm{dL}$ in non-exposed participants [17]. Recently, a study in India also showed that the mean BLL was $30.5 \pm 12.2 \mu \mathrm{g} / \mathrm{dL}$ in spray paint workers and $5.46 \pm 2.58 \mu \mathrm{g} / \mathrm{dL}$ in the control group [7]. In South Korea, Jung et al. performed a study among workers who worked in secondary lead smelter, plastic stabilizer, and radiator manufacturing industries and showed that the mean BLL in highly exposed, moderately exposed, lowly exposed, and non-exposed participants was $74.6 \pm 7.8,46.5 \pm 5.9,24.3 \pm 2.7$, and $7.9 \pm 1.4 \mu \mathrm{g} / \mathrm{dL}$, respectively [39]. In Taiwan, a study by Hsiao et al. among lead battery factory workers showed that the mean BLL was $15.8 \mu \mathrm{g} / \mathrm{dL}$ and $11.6 \mu \mathrm{g} / \mathrm{dL}$ in males and females, respectively [62].

The pooled mean difference in BLL between the exposed males and females showed that the mean BLL in the exposed males was higher than that in the female participants. A significant difference in gender was clearly observed in a study by Staessen et al. [54] and Wang et al. [19]. However, a study by Lai et al. [11] demonstrated that BLL in exposed males was lower than that in female participants. The heterogeneity of the results between the studies might have been because males were more likely to be exposed to lead than females. Another possible explanation is that estrogen is higher in females than males; therefore, estrogen may increase lead distribution to the bone and slow the release of lead from the bone in women as well $[63,64]$.

The present meta-analysis demonstrated the difference in the mean BUN, serum creatinine, and mean creatinine clearance in lead-exposed participants compared to non-exposed participants. In addition, the present meta-analysis showed that the mean BUN was significantly higher in lead-exposed participants than in non-exposed participants, especially in participants with high and moderate mean BLL. These results demonstrated that an increase in BLL could induce renal impairment among exposed participants. The difference in BUN was clearly observed in five included studies [15,17,39,49,59]. Nevertheless, some included studies demonstrated no difference in BUN between the two groups of participants $[7,20,32]$ and caused heterogeneity among the studies included in the meta-analysis. A high mean BUN was also reported in lead battery workers and spray painters in India [7] and Taiwan [19], in a secondary lead refinery worker in South Korea [39] and Japan [65], and in lead workers in Nigeria [17] and India [49]. Moreover, Wang et al. demonstrated that every increment of $10 \mu \mathrm{g} / \mathrm{dL}$ BLL produced an increase of $0.62 \mathrm{mg} / \mathrm{dL}$ in BUN levels [19]. The increase in BUN might be caused by the reduction in renal plasma flow and the decrease in the glomerular filtration rate (GFR), leading to high accumulations of urea nitrogen in the plasma [66]. The meta-regression analysis between BLL and BUN demonstrated that the mean BLL was an independent factor affecting BUN levels. This result suggested that BUN is a sensitive marker of lead-induced renal impairment. In addition to the lead that affected the BUN levels, there were other factors, such as age, work duration, gender, and smoking habit [19].

The present meta-analysis showed that the mean creatinine was significantly higher in lead-exposed participants than in non-exposed participants, especially in participants 
with a high mean BLL. The higher mean creatinine among the exposed participants with a high mean BLL was clearly demonstrated in four studies $[7,15,16,59]$. High mean levels of creatinine were observed in various studies, such as the study by de Pinto Almeida et al., which studied Brazilian lead workers [16]; the studies of Onuegbu et al. [17] and Alasia et al. [61], which examined Nigerian lead workers; and the study of Kshirsagar Mandakini et al., which studied spray painters in India [7]. Nevertheless, five studies [17,32,33,39,49] demonstrated no difference in the mean creatinine between the two groups of participants. A study by Roels et al. [20] showed a lower mean creatinine in exposed participants than in non-exposed participants. Despite the high mean level of creatinine in the leadexposed workers that was observed, the meta-regression showed no relationship between the mean BLL and creatinine level. Some previous studies reported similar findings to ours $[32,39,49]$. This might be because kidneys have millions of nephrons and have reserve capacity; therefore, the clinical manifestations of renal impairment would not be demonstrated until the nephrons were destroyed by more than 50\% [49]. This indicated that serum creatinine was insufficiently sensitive for the early detection of renal impairment induced by lead. The non-association of BLL and creatinine might be due to factors related to creatinine balance, such as gender, age, weight, work duration, smoking habits, and alcohol consumption, which also affect serum creatinine [19].

Creatinine clearance has been widely used to determine GFR. It is commonly used in routine laboratory work for evaluating renal function. This study demonstrated that the mean creatinine clearance was significantly lower in lead-exposed workers than in non-exposed participants. This finding was observed in the studies by Alasia et al. [61], Gennart et al. [33], Weaver et al. [59], Chen et al. [30], and Reilly et al. [51]. Nevertheless, the meta-regression analyses did not show the relationship between the mean BLL and creatinine clearance. This finding is consistent with a study on lead-exposed workers in Japan [48], which indicated that a BLL less than $70 \mu \mathrm{g} / \mathrm{dL}$ might not affect the function of the glomeruli [54]. Furthermore, various confounding factors, such as ethnicity, age, gender, work duration, muscle mass, and protein intake, might influence creatinine clearance $[19,44]$. These confounding factors might, in part, affect the analysis of BLL and creatinine clearance.

Uric acid is the product of purine metabolism; moreover, it is derived from the degradation of a cell or nucleic acid within a cell, and elimination of uric acid occurs in the proximal tubule and distal tubule [67]. A previous study indicated that chronic lead exposure may interfere with the secretion of uric acid in the distal tubule, leading to hyperuricemia [68]. However, certain mechanisms of hyperuricemia induced by lead are still unclear. The present meta-analysis demonstrated no difference in the uric acid level between lead-exposed and non-exposed participants. Nevertheless, the exposed participants with a high BLL seemed to have a higher uric acid level, as demonstrated in four included studies [7,15,16,32]. In addition, a study by Kshirsagar et al. [41] demonstrated that exposed participants with a moderate BLL had a higher uric acid level than the control participants. Three studies demonstrated no difference in the serum uric acid level between the two groups of participants $[20,39,47]$. In addition, some previous studies contradicted our study $[16,41,61]$. These studies reported an increase in the uric acid level of lead-exposed workers who had a BLL greater than $60 \mu \mathrm{g} / \mathrm{dL}$. Although the meta-analysis demonstrated a difference in the uric acid level between the two groups of participants, the meta-regression showed no association between BLL and mean uric acid. Therefore, the change in uric acid was insufficient as a sensitive marker to detect early renal impairment induced by lead exposure.

In addition to renal impairment induced by lead, lead exposure also increased the severity of underlying diseases, especially in susceptible populations with hypertension, diabetes mellitus, and chronic kidney disease [8]. Moreover, cadmium, mercury, and other heavy metals contaminating the environment and workplace may result in combined adverse effects on the human body. Therefore, protection from heavy metal exposure is crucial; for example, factory owners should provide occupational health educational 
programs to prevent workers from being poisoned by lead. In addition, lead exposure prevention should be implemented before, while and after the work is finished, for example, wearing personal protection devices, such as gloves, masks, and aprons, before starting to work, hand washing prior to eating, not smoking or eating in the workplace, and cleaning the body and mandatorily changing clothes before leaving the workplace to reduce the distribution of lead into the environment [65]. Although the removal and return of lead-exposed workers at 60 and $40 \mu \mathrm{g} / \mathrm{dL}$, respectively, is used by the United States Occupational Safety and Health Administration (US OSHA) [69] and presumably by other countries, the results of the present study suggested that workers who have an excessive BLL of $30 \mu \mathrm{g} / \mathrm{dL}$ should be removed from their job and return to work when their BLL drops below $20 \mu \mathrm{g} / \mathrm{dL}$.

\section{Limitations}

The present study had limitations. First, there were a limited number of included studies based on the eligibility criteria, which limited the study to adult or middle-aged participants. Second, the relationship between BLL and work duration was not assessed due to data unavailability among the included studies. Third, there are several factors that affect the progression of lead nephropathy in addition to lead, including individual susceptibility, race, and the pattern of lead exposure [39]. These might be the reasons for the heterogeneity among the included studies, where renal impairment was found to be related to lead exposure.

\section{Conclusions}

BLL was associated with abnormal renal function test parameters, including high BUN, high creatinine, and low creatinine clearance. Moreover, BUN seemed to be the most valuable prognostic marker for lead-induced renal impairment. Therefore, regular checks for renal function among lead-exposed workers should be important and publicly advocated for.

Supplementary Materials: The following are available online at https:/ /www.mdpi.com/article/10 $.3390 /$ ijerph18084174/s1. Supplementary Figure S1. The mean difference in uric acid levels between exposed and control participants, Supplementary Figure S2. The mean difference in creatinine clearance between exposed and control participants, Supplementary Figure S3. The meta-regression analysis of WMD and creatinine clearance, Supplementary Figure S4. The meta-regression analysis of WMD and uric acid, Supplementary Tables, Table S1. Search terms, Table S2. Quality of the included studies, PRISMA Checklist S1.

Author Contributions: S.K. and M.K. designed the study. M.K. performed the data collection and statistical analysis, in addition to drafting the methods and results sections of the manuscript. S.K. drafted the introduction and discussion sections of the manuscript. All authors have read and agreed to the published version of the manuscript.

Funding: Not applicable.

Institutional Review Board Statement: Not applicable.

Informed Consent Statement: Not applicable.

Data Availability Statement: The dataset used and analyzed during the current study is available from the corresponding author upon reasonable request.

Acknowledgments: We would also like to thank David C. Chang for proofreading the manuscript.

Conflicts of Interest: The authors declare that they have no competing interests. 


\begin{tabular}{ll}
\multicolumn{2}{l}{ Abbreviation } \\
BLL & Blood lead level \\
BUN & Blood urea nitrogen \\
CI & Confidence Interval \\
CRCL & Creatinine clearance \\
eGFR & estimated Glomerular Filtration Rate \\
GF & Glomerular function \\
KNHANES & The Korea Nation Health and Nutrition Examination Survey \\
NS & Not specified \\
PbB & Blood lead \\
PVC & Polyvinyl chloride \\
Ref & Reference number \\
WMD & Weighted Mean Difference \\
mg/dL & milligrams per deciliter \\
$\mu \mathrm{g} / \mathrm{dL}$ & micrograms per deciliter
\end{tabular}

\section{References}

1. Wani, A.L.; Ara, A.; Usmani, J.A. Lead toxicity: A review. Interdiscip. Toxicol. 2015, 8, 55-64. [CrossRef] [PubMed]

2. Sun, Y.; Zhou, Z.; Zhu, G.; Lei, L.; Zhang, H.; Chang, X.; Jin, T. Estimation of Benchmark Dose for Bone Damage and Renal Dysfunction in a Chinese Male Population Occupationally Exposed to Lead. Ann. Occup. Hyg. 2008, 52, 527-533. [CrossRef]

3. Harari, F.; Sallsten, G.; Christensson, A.; Petkovic, M.; Hedblad, B.; Forsgard, N.; Melander, O.; Nilsson, P.M.; Borné, Y.; Engström, G.; et al. Blood Lead Levels and Decreased Kidney Function in a Population-Based Cohort. Am. J. Kidney Dis. 2018, 72, 381-389. [CrossRef]

4. Nakhaee, S.; Amirabadizadeh, A.; Brent, J.; Mehrpour, O. Impact of chronic lead exposure on liver and kidney function and haematologic parameters. Basic Clin. Pharmacol. Toxicol. 2019, 124, 621-628. [CrossRef] [PubMed]

5. Tsoi, M.-F.; Cheung, C.-L.; Cheung, T.T.; Cheung, B.M.Y. Continual Decrease in Blood Lead Level in Americans: United States National Health Nutrition and Examination Survey 1999-2014. Am. J. Med. 2016, 129, 1213-1218. [CrossRef] [PubMed]

6. Yimthiang, S.; Waeyang, D.; Kuraeiad, S. Screening for Elevated Blood Lead Levels and Related Risk Factors among Thai Children Residing in a Fishing Community. Toxics 2019, 7, 54. [CrossRef] [PubMed]

7. Kshirsagar Mandakini, S.; Patil Jyotsna, A.; Patil Arun, J. Elevated blood lead level alters the liver and kidney function tests of spray painters. Pravara. Med. Rev. 2020, 12, 31-36.

8. Vlasak, T.; Jordakieva, G.; Gnambs, T.; Augner, C.; Crevenna, R.; Winker, R.; Barth, A. Blood lead levels and cognitive functioning: A meta-analysis. Sci. Total Environ. 2019, 668, 678-684. [CrossRef] [PubMed]

9. Landrigan, P.J. Current issues in the epidemiology and toxicology of occupational exposure to lead. Environ. Health Perspect. 1990, 89, 61-66. [CrossRef] [PubMed]

10. Weaver, V.M.; Griswold, M.; Todd, A.C.; Jaar, B.G.; Ahn, K.-D.; Thompson, C.B.; Lee, B.-K. Longitudinal associations between lead dose and renal function in lead workers. Environ. Res. 2009, 109, 101-107. [CrossRef] [PubMed]

11. Lai, L.-H.; Chou, S.-Y.; Wu, F.-Y.; Chen, J.J.-H.; Kuo, H.-W. Renal dysfunction and hyperuricemia with low blood lead levels and ethnicity in community-based study. Sci. Total Environ. 2008, 401, 39-43. [CrossRef] [PubMed]

12. Pergande, M.; Jung, K.; Precht, S.; Fels, L.M.; Herbort, C.; Stolte, H. Changed excretion of urinary proteins and enzymes by chronic exposure to lead. Nephrol. Dial. Transplant. 1994, 9, 613-618. [CrossRef] [PubMed]

13. Ehrlich, R.; Robins, T.G.; Jordaan, E.; Miller, S.; Mbuli, S.; Selby, P.B.; Wynchank, S.; Cantrell, A.C.; De Broe, M.; Dhaese, P.C.; et al. Lead absorption and renal dysfunction in a South African battery factory. Occup. Environ. Med. 1998, 55, 453-460. [CrossRef] [PubMed]

14. Weaver, V.M.; Jaar, B.G.; Schwartz, B.S.; Todd, A.C.; Ahn, K.-D.; Lee, S.-S.; Wen, J.; Parsons, P.J.; Lee, B.-K. Associations among Lead Dose Biomarkers, Uric Acid, and Renal Function in Korean Lead Workers. Environ. Health Perspect. 2005, 113, 36-42. [CrossRef] [PubMed]

15. Alasia, D.D.; Emem-Chioma, P.C.; Wokoma, F.S. Association of lead exposure, serum uric acid and parameters of renal function in Nigerian lead-exposed workers. Int. J. Occup. Environ. Med. 2010, 1, 182-190. [PubMed]

16. de Pinto Almeida, A.R.; Martins Carvalho, F.; Galvão Spinola, A.; Rocha, H. Renal dysfunction in brazilian lead workers. Am. J. Nephrol. 1987, 7, 455-458. [CrossRef] [PubMed]

17. Onuegbu, A.; Olisekodiaka, M.; Nwaba, E.; Adeyeye, A.; Akinola, F. Assessment of some renal indices in people occupationally exposed to lead. Toxicol. Ind. Health 2010, 27, 475-479. [CrossRef] [PubMed]

18. Gounden, V.; Bhatt, H.; Jialal, I. Renal Function Tests. In StatPearls; EDN: Treasure Island, FL, USA, 2021.

19. Wang, V.-S.; Lee, M.-T.; Chiou, J.-Y.; Guu, C.-F.; Wu, C.-C.; Wu, T.-N.; Lai, J.-S. Relationship between blood lead levels and renal function in lead battery workers. Int. Arch. Occup. Environ. Health 2002, 75, 569-575. [CrossRef] [PubMed] 
20. Roels, H.; Lauwerys, R.; Konings, J.; Buchet, J.-P.; Bernard, A.; Green, S.; Bradley, D.; Morgan, W.; Chettle, D. Renal function and hyperfiltration capacity in lead smelter workers with high bone lead. Occup. Environ. Med. 1994, 51, 505-512. [CrossRef] [PubMed]

21. Azami, M.; Tardeh, Z.; Mansouri, A.; Soleymani, A.; Sayehmiri, K. Mean Blood Lead Level in Iranian Workers: A Systematic and Meta-Analysis. Iran. Red Crescent Med. J. 2018, 20. [CrossRef]

22. Moher, D.; Liberati, A.; Tetzlaff, J.; Altman, D.G.; The PRISMA Group. Preferred reporting items for systematic reviews and meta-analyses: The PRISMA statement. PLoS Med. 2009, 6, e1000097. [CrossRef]

23. International Prospective Register of Systematic Reviews. Available online: https://www.crd.york.ac.uk/prospero/ (accessed on 15 January 2021).

24. The Newcastle-Ottawa Scale (NOS) for Assessing the Quality of Nonrandomised Studies in Meta-Analyses. Available online: http:/ / www.ohri.ca/programs/clinical_epidemiology/oxford.asp (accessed on 20 January 2021).

25. Lim, Y.C.; Chia, K.S.; Ong, H.Y.; Ng, V.; Chew, Y.L. Renal dysfunction in workers exposed to inorganic lead. Ann. Acad. Med. Singap. 2001, 30, 112-117.

26. Hozo, S.P.; Djulbegovic, B.; Hozo, I. Estimating the mean and variance from the median, range, and the size of a sample. BMC Med Res. Methodol. 2005, 5, 13. [CrossRef] [PubMed]

27. The Standard for Clinical Calculations \& Quantitative Analysis in Medicine. Available online: http://www.scymed.com/ (accessed on 25 January 2021).

28. Higgins, J.P.T.; Chandler, J.; Cumpston, M.; Li, T.; Page, M.J.; Welch, V.A. (Eds.) Cochrane Handbook for Systematic Reviews of Interventions version 6.2 (updated February 2021). In Cochrane; Wiley: Hoboken, NJ, USA, 2021.

29. Buser, M.C.; Ingber, S.Z.; Raines, N.; Fowler, D.A.; Scinicariello, F. Urinary and blood cadmium and lead and kidney function: NHANES 2007-2012. Int. J. Hyg. Environ. Health 2016, 219, 261-267. [CrossRef] [PubMed]

30. Chen, X.; Zhu, G.; Wang, Z.; Zhou, H.; He, P.; Liu, Y.; Jin, T. The association between lead and cadmium co-exposure and renal dysfunction. Ecotoxicol. Environ. Saf. 2019, 173, 429-435. [CrossRef] [PubMed]

31. Chung, S.; Chung, J.H.; Kim, S.J.; Koh, E.S.; Yoon, H.E.; Park, C.W.; Chang, Y.S.; Shin, S.J. Erratum to: Blood lead and cadmium levels and renal function in Korean adults. Clin. Exp. Nephrol. 2014, 18, 735-736. [CrossRef]

32. Dioka, C.E.; Orisakwe, O.E.; Adeniyi, F.A.; Meludu, S.C. Liver and Renal Function Tests in Artisans Occupationally Exposed to Lead in Mechanic Village in Nnewi, Nigeria. Int. J. Environ. Res. Public Health 2004, 1, 21-25. [CrossRef] [PubMed]

33. Gennart, J.-P.; Bernard, A.; Lauwerys, R. Assessment of thyroid, testes, kidney and autonomic nervous system function in lead-exposed workers. Int. Arch. Occup. Environ. Health 1992, 64, 49-57. [CrossRef]

34. Gerhardsson, L.; Börjesson, J.; Grubb, A.; Hultberg, B.; Mattsson, S.; Schütz, A.; Skerfving, S. In vivo XRF as a means to evaluate the risk of kidney effects in lead and cadmium exposed smelter workers. Appl. Radiat. Isot. 1998, 49, 711-712. [CrossRef]

35. Gerhardsson, L.; Chettle, D.R.; Englyst, V.; Nordberg, G.F.; Nyhlin, H.; Scott, M.C.; Todd, A.C.; Vesterberg, O. Kidney effects in long term exposed lead smelter workers. Occup. Environ. Med. 1992, 49, 186-192. [CrossRef] [PubMed]

36. Goswami, K.; Bhattacharya, B. Renal function in lead exposed urban population. Poll. Res. 2001, 20, $395-399$.

37. Hernández-Serrato, M.I.; Fortoul, T.I.; Rojas-Martínez, R.; Mendoza-Alvarado, L.R.; Canales-Treviño, L.; Bochichio-Riccardelli, T.; Ávila-Costa, M.R.; Olaiz-Fernández, G. Lead blood concentrations and renal function evaluation: Study in an exposed Mexican population. Environ. Res. 2006, 100, 227-231. [CrossRef] [PubMed]

38. Jain, R.B. Lead and kidney: Concentrations, variabilities, and associations across the various stages of glomerular function. J. Trace Elements Med. Biol. 2019, 54, 36-43. [CrossRef] [PubMed]

39. Jung, K.-Y.; Lee, S.-J.; Kim, J.-Y.; Hong, Y.-S.; Kim, S.-R.; Kim, D.; Song, J.-B.; Kim, N.-I. Renal Dysfunction Indicators in Lead Exposed Workers. J. Occup. Health 1998, 40, 103-109. [CrossRef]

40. Kim, R.; Rotnitsky, A.; Sparrow, D.; Weiss, S.; Wager, C.; Hu, H. A longitudinal study of low-level lead exposure and impairment of renal function. The Normative Aging Study. JAMA 1996, 275, 1177-1181. [CrossRef] [PubMed]

41. Kshirsagar, M.S.; Patil, A.J.; Patil, J. Impact of Occupational Lead Exposure on Liver and Kidney Function Tests on Silver Jewellery Workers. J. Clin. Diagn. Res. 2019, 13. [CrossRef]

42. Lin, T.; Tai-Yi, J. Benchmark dose approach for renal dysfunction in workers exposed to lead. Environ. Toxicol. 2007, 22, 229-233. [CrossRef]

43. Jialun, F.; Liu, X.; Deng, Q.; Duan, Y.; Dai, H.; Li, Y.; Xiaohui, L.; Ning, X.; Fan, J.; Zhou, L.; et al. Continuous Lead Exposure Increases Blood Pressure but Does Not Alter Kidney Function in Adults 20-44 Years of Age in a Lead-Polluted Region of China. Kidney Blood Press. Res. 2015, 40, 207-214. [CrossRef]

44. Mujaj, B.; Yang, W.-Y.; Zhang, Z.-Y.; Wei, F.-F.; Thijs, L.; Verhamme, P.; Staessen, J. Renal function in relation to low-level environmental lead exposure. Nephrol. Dial. Transplant. 2018, 34, 941-946. [CrossRef]

45. Muntner, P.; He, J.; Vupputuri, S.; Coresh, J.; Batuman, V. Blood lead and chronic kidney disease in the general United States population: Results from NHANES III. Kidney Int. 2003, 63, 1044-1050. [CrossRef]

46. Navas-Acien, A.; Tellez-Plaza, M.; Guallar, E.; Muntner, P.; Silbergeld, E.; Jaar, B.; Weaver, V. Blood Cadmium and Lead and Chronic Kidney Disease in US Adults: A Joint Analysis. Am. J. Epidemiol. 2009, 170, 1156-1164. [CrossRef] [PubMed]

47. Oktem, F.; Arslan, M.K.; Dündar, B.; Delibas, N.; Gültepe, M.; Ilhan, I.E. Renal effects and erythrocyte oxidative stress in long-term low-level lead-exposed adolescent workers in auto repair workshops. Arch. Toxicol. 2004, 78, 681-687. [CrossRef] [PubMed] 
48. Omae, K.; Sakurai, H.; Higashi, T.; Muto, T.; Ichikawa, M.; Sasaki, N. No adverse effects of lead on renal function in lead-exposed workers. Ind. Health 1990, 28, 77-83. [CrossRef] [PubMed]

49. Patil, A.J.; Bhagwat, V.R.; Patil, J.; Dongre, N.N.; Ambekar, J.G.; Das, K.K. Occupational lead exposure in battery manufacturing workers, silver jewelry workers, and spray painters in western Maharashtra (India): Effect on liver and kidney function. J. Basic Clin. Physiol. Pharmacol. 2007, 18, 87-100. [CrossRef] [PubMed]

50. Payton, M.; Hu, H.; Sparrow, D.; Weiss, S.T. Low-level Lead Exposure and Renal Function in the Normative Aging Study. Am. J. Epidemiol. 1994, 140, 821-829. [CrossRef] [PubMed]

51. Reilly, R.; Spalding, S.; Walsh, B.; Wainer, J.; Pickens, S.; Royster, M.; Villanacci, J.; Little, B.B. Chronic Environmental and Occupational Lead Exposure and Kidney Function among African Americans: Dallas Lead Project II. Int. J. Environ. Res. Public Health 2018, 15, 2875. [CrossRef] [PubMed]

52. Satarug, S.; Nishijo, M.; Ujjin, P.; Vanavanitkun, Y.; Baker, J.R.; Moore, M.R. Evidence for Concurrent Effects of Exposure to Environmental Cadmium and Lead on Hepatic CYP2A6 Phenotype and Renal Function Biomarkers in Nonsmokers. Environ. Health Perspect. 2004, 112, 1512-1518. [CrossRef] [PubMed]

53. Staessen, J.; Yeoman, W.B.; Fletcher, A.; Markowe, H.L.; Marmot, M.G.; Rose, G.; Semmence, A.; Shipley, M.J.; Bulpitt, C.J. Blood lead concentration, renal function, and blood pressure in London civil servants. Occup. Environ. Med. 1990, 47, 442-447. [CrossRef] [PubMed]

54. Staessen, J.A.; Lauwerys, R.R.; Buchet, J.-P.; Bulpitt, C.J.; Rondia, D.; Vanrenterghem, Y.; Amery, A. Impairment of Renal Function with Increasing Blood Lead Concentrations in the General Population. N. Engl. J. Med. 1992, 327, 151-156. [CrossRef]

55. Tsaih, S.-W.; Korrick, S.; Schwartz, J.; Amarasiriwardena, C.; Aro, A.; Sparrow, D.; Hu, H. Lead, Diabetes, Hypertension, and Renal Function: The Normative Aging Study. Environ. Health Perspect. 2004, 112, 1178-1182. [CrossRef]

56. Verschoor, M.; Wibowo, A.; Herber, R.; Van Hemmen, J.; Zielhuis, R. Influence of occupational low-level lead exposure on renal parameters. Am. J. Ind. Med. 1987, 12, 341-351. [CrossRef]

57. Wang, X.; Liang, H.; Wang, Y.; Cai, C.; Li, J.; Li, X.; Wang, M.; Chen, M.; Xu, X.; Tan, H. Risk factors of renal dysfunction and their interaction in level-low lead exposure paint workers. BMC Public Health 2018, 18, 526. [CrossRef] [PubMed]

58. Weaver, V.M.; Kim, N.-S.; Jaar, B.G.; Schwartz, B.S.; Parsons, P.J.; Steuerwald, A.J.; Todd, A.C.; Simon, D.; Lee, B.-K. Associations of low-level urine cadmium with kidney function in lead workers. Occup. Environ. Med. 2010, 68, 250-256. [CrossRef]

59. Weaver, V.M.; Lee, B.-K.; Ahn, K.-D.; Lee, G.-S.; Todd, A.C.; Stewart, W.F.; Wen, J.; Simon, D.J.; Parsons, P.J.; Schwartz, B.S. Associations of lead biomarkers with renal function in Korean lead workers. Occup. Environ. Med. 2003, 60, 551-562. [CrossRef] [PubMed]

60. Weaver, V.M.; Lee, B.-K.; Todd, A.C.; Jaar, B.G.; Ahn, K.-D.; Wen, J.; Shi, W.; Parsons, P.J.; Schwartz, B.S. Associations of Patella Lead and Other Lead Biomarkers With Renal Function in Lead Workers. J. Occup. Environ. Med. 2005, 47, 235-243. [CrossRef] [PubMed]

61. Alasia, D.; Emem-Chioma, P.; Wokoma, S. Occupational and Environmental Lead Exposure in Port Harcourt, Nigeria: Analysis of its association with renal function indices. Niger. J. Med. 2010, 19, 407-414. [CrossRef] [PubMed]

62. Hsiao, C.-Y.; Wu, H.-D.I.; Lai, J.-S.; Kuo, H.-W. A longitudinal study of the effects of long-term exposure to lead among lead battery factory workers in Taiwan (1989-1999). Sci. Total Environ. 2001, 279, 151-158. [CrossRef]

63. Falq, G.; Zeghnoun, A.; Pascal, M.; Vernay, M.; Le Strat, Y.; Garnier, R.; Olichon, D.; Bretin, P.; Castetbon, K.; Fréry, N. Blood lead levels in the adult population living in France the French Nutrition and Health Survey (ENNS 2006-2007). Environ. Int. 2011, 37, 565-571. [CrossRef] [PubMed]

64. Bjermo, H.; Sand, S.; Nälsén, C.; Lundh, T.; Barbieri, H.E.; Pearson, M.; Lindroos, A.K.; Jönsson, B.A.; Barregård, L.; Darnerud, P.O. Lead, mercury, and cadmium in blood and their relation to diet among Swedish adults. Food Chem. Toxicol. 2013, 57, 161-169. [CrossRef] [PubMed]

65. Endo, G.; Horiguchi, S.; Kiyota, I. Urinary N-acetyl-beta-D-glucosaminidase activity in lead-exposed workers. J. Appl. Toxicol. 1990, 10, 235-238. [CrossRef] [PubMed]

66. Campbell, B.C.; Beattie, A.D.; Moore, M.R.; Goldberg, A.; Reid, A.G. Renal insufficiency associated with excessive lead exposure. BMJ 1977, 1, 482-485. [CrossRef] [PubMed]

67. Maiuolo, J.; Oppedisano, F.; Gratteri, S.; Muscoli, C.; Mollace, V. Regulation of uric acid metabolism and excretion. Int. J. Cardiol. 2016, 213, 8-14. [CrossRef] [PubMed]

68. Loghman-Adham, M. Renal effects of environmental and occupational lead exposure. Environ. Health Perspect. 1997, 105, 928-938. [CrossRef] [PubMed]

69. Lead. Available online: https://www.osha.gov/lead/health-effects (accessed on 1 February 2021). 